\title{
Changing Causes of Drought in the Urmia Lake Basin-Increasing Influence of Evaporation and Disappearing Snow Cover
}

\author{
Maral Habibi ${ }^{1, *}$, Iman Babaeian ${ }^{2} \mathbb{D}$ and Wolfgang Schöner ${ }^{1}$ \\ 1 Department of Geography and Regional Science, University of Graz, 8010 Graz, Austria; \\ wolfgang.schoener@uni-graz.at \\ 2 Climate Research Institute, Atmospheric Science and Meteorological Research Center, \\ Mashhad 91735-676, Iran; i.babaeian@gmail.com \\ * Correspondence: maral.habibi@uni-graz.at; Tel.: +43-(0)316-380-5678
}

Citation: Habibi, M.; Babaeian, I.; Schöner, W. Changing Causes of Drought in the Urmia Lake Basin-Increasing Influence of Evaporation and Disappearing Snow Cover. Water 2021, 13, 3273. https:// doi.org/10.3390/w13223273

Academic Editor: Alina Barbulescu

Received: 9 October 2021

Accepted: 15 November 2021

Published: 18 November 2021

Publisher's Note: MDPI stays neutral with regard to jurisdictional claims in published maps and institutional affiliations.

Copyright: (c) 2021 by the authors. Licensee MDPI, Basel, Switzerland. This article is an open access article distributed under the terms and conditions of the Creative Commons Attribution (CC BY) license (https:// creativecommons.org/licenses/by/ $4.0 /)$.

\begin{abstract}
The water level of the Urmia Lake Basin (ULB), located in the northwest of Iran, started to decline dramatically about two decades ago. As a result, the area has become the focus of increasing scientific research. In order to improve understanding of the connections between declining lake level and changing local drought conditions, three common drought indices are employed to analyze the period 1981-2018: The Standard Precipitation Index (SPI), the Standard PrecipitationEvaporation Index (SPEI), and the Standardized Snow Melt and Rain Index (SMRI). Although rainfall is a significant indicator of water availability, temperature is also a key factor since it determines rates of evapotranspiration and snowmelt. These different processes are captured by the three drought indices mentioned above to describe drought in the catchment. Therefore, the main objective of this paper is to provide a comparative analysis of drought over the ULB by incorporating different drought indices. Since there is not enough long-term observational data of sufficiently high density for the ULB region, ECMWF Reanalysis data version 5(ERA5) has been used to estimate SPI, SPEI, and SMRI drought indicators. These are shown to work well, with AUC-ROC $>0.9$, in capturing different classes of basin drought characteristics. The results show a downward trend for SPEI and SMRI (but not for SPI), suggesting that both evaporation and lack of snowmelt exacerbate droughts. Owing to the increasing temperatures in the basin and the decrease in snowfall, drought events have become particularly pronounced in the SPEI and SMRI time series since 1995. No significant SMRI drought was detected prior to 1995, thus indicating that sufficient snowfall was available at the beginning of the study period. The study results also reveal that the decrease in lake water level from 2010 to 2018 was not only caused by changes in the water balance components, but also by unsustainable water management.
\end{abstract}

Keywords: Urmia Lake Basin; drought; climate change; snow cover; evapotranspiration; ERA5; extremes

\section{Introduction}

Droughts are significant natural hazards worldwide, with widespread impacts on humans and ecosystems. While the frequency and magnitude of droughts are expected to change in the coming decades due to climate change, the regional evolution of future droughts remains highly uncertain [1,2]. The Middle East and southwest Asia are waterstressed regions, societally vulnerable, and prone to severe droughts. Since the 1940s, there have been two particularly severe drought periods in these regions, 1999-2001 and 2007-2008, respectively [3-5]. Different drought indices have confirmed that 2001 was one of the most severe periods of drought in Iran [6,7]. Studies regarding the periodic behavior of drought in Iran show that, in addition to the dominant short-term periods over the northwest of Iran, long-term periods of 10 and 30 years have also been observed. Although 
the average rainfall in southern Iran is much lower than in the north, short-term droughts in the north are more severe than in the south. Meanwhile, long-term droughts are more severe in Iran's west, east, southeast, south, and center [8-10].

Large-scale atmospheric circulation and teleconnection play an essential role in the development of drought in Iran. Dry periods are usually accompanied by westward displacement of a subtropical high, while wet periods are associated with eastward displacement of the high-pressure system toward the Arabian Sea. The Southern Oscillation Index (SOI) in its positive phase can decrease precipitation in the northwest of Iran [11]. Research has also confirmed that the late withdrawal of the Indian monsoon is associated with a delay in the onset of fall precipitation over Iran. This delay is accompanied by prolonged subtropical high pressure settling over Iran's plateau, with the latter preventing the formation of polar jet frontal systems [12-15].

Northwestern Iran has the highest risk of severe and long-lasting drought [16], and the shrinking of the Urmia Lake has been quite dramatic over the last two decades. Whether or not this is an effect of ongoing climate change or is the result of human activity, such as water management (e.g., water dams and unapproved wells) or agriculture $[17,18]$, is the subject of considerable debate. The declining water level of Lake Urmia is now a major challenge in national water and environmental management. In addition, climate change and reduced precipitation [19-21], decreased water levels [22], and the expansion of saline areas around the lake have also all led to numerous environmental and economic impacts [23]. Over the Urmia Lake basin, a warming trend of $0.18^{\circ} \mathrm{C} /$ decade has been detected, and precipitation has decreased by approximately $9 \mathrm{~mm} /$ decade [24]. This has resulted in an increase in evaporation from the lake of $6.2 \mathrm{~mm} /$ decade [24]. Consequently, the water level of Lake Urmia has been rapidly declining since 1995, with a $6.1 \mathrm{~m}$ decline for the period 1995-2009. The lake surface area has also decreased by about $-188.3 \mathrm{~km}^{2} / \mathrm{yr}$, from $5503 \mathrm{~km}^{2}$ in 1998 to $2323 \mathrm{~km}^{2}$ in 2011. Mean precipitation in the ULB has decreased by $9.2 \%$, and the average maximum temperature has increased by $0.8^{\circ} \mathrm{C}$ over 1964-2005 [25]. The leading cause of the recession of Lake Urmia is the diminution of inflow from rivers [19,24,26-28]. Aziz et al. [29] found that compared with other impacts, the operation of dams (26\%) and increasing water demand $(16 \%)$ have played a clear role in reducing the water input to the lake. Changing climate contributed up to 16\% of the lake level change within 1999-2014. The lake reached its highest level in 1995, but it has generally declined since then, reaching the lowest level in recent years $[19,23,30]$. The mean annual water inflow into the lake is $6900 \times 10^{6} \mathrm{~m}^{3}$, of which $4900 \times 10^{6} \mathrm{~m}^{3}$ is from rivers (with $2000 \times 10^{6} \mathrm{~m}^{3}$ of this coming from the river Zarrineh Rood), $500 \times 10^{6} \mathrm{~m}^{3}$ from floodwaters, and $1500 \times 10^{6} \mathrm{~m}^{3}$ from precipitation onto the lake [31]. However, as water inflow into the lake has also recently declined [19,26], Lake Urmia's surface area and volume have continued to decrease [24].

The decline in the lake's water level and surface area [26] over the last two decades has caused an environmental disaster, led to increased salinity, and negatively affected agriculture, livelihoods, and health [32,33]. The strong natural climatic variability is being threatened and amplified by climate change, thus increasing the occurrence of hydrologically extreme drought events [34]. The impact of drought, particularly its socioeconomic impact, means that substantial improvements in water management practices are required in order to preserve or partially restore the lake [24]. Data from weather stations located in the ULB indicate that an increase in drought is to be expected in the future [35]. Salt storms around the former shoreline and lakebed have already begun to sweep across the region [36], negatively impacting local agriculture and adversely influencing human health [24].

Drought may be analyzed in terms of its duration, severity, spatial coverage, and water deficit characteristics. Several methods and indices have been developed based on climatic and hydrological variables to monitor and quantify drought intensity and impacts. These cover factors such as precipitation [37-39], soil humidity [40], evapotranspiration and vegetation conditions [41-43], or combine these in a number of specific indices [44-47]. Analyzing the impact of global climate change on drought has also become common [35]. 
Over the past few decades, new indices have been developed for drought quantification, and apart from data on precipitation, they have added variables such as temperature, snowpack, evapotranspiration, soil moisture, runoff, streamflow, groundwater, reservoir storage, and snowmelt [37-41,48-52].

Despite the many existing studies of the ULB, drought quantification remains an ongoing issue of high practical value. The present study focuses on quantifying drought for the ULB by using SPI, SPEI, and SMRI, and looks at precipitation, evapotranspiration, and snowmelt as the major components of water balance.

Snow droughts remain relatively unexplored compared to other drought types, and only a few studies have included snow information in drought characterization [41,52-57]. Snow droughts have become more prevalent, intensified, and prolonged across the Western United States. In addition, Eastern Russia, Europe, and the US have emerged as snow drought hotspots, with respective increases in drought duration of $\sim 2 \%, 16 \%$, and $28 \%$ in recent decades. While runoff from mountain snowmelt can support agricultural activities in downstream areas (e.g., California's Central Valley), snow also directly provides meltwater to croplands and protects winter wheat from frost and freezing (e.g., in Russia and Ukraine) [58]. The gradual increase in temperature in some regions in North America, such as the Athabasca River Basin (ARB), Central North America, and Alaska, resulting in snowpack melting in early spring, has already been described [59-61]. A snow drought or a deficit in snow water equivalent (SWE is the amount of water obtained if the snowpack is melted instantaneously) can have severe regional and global impacts on human activities and ecosystems, both in snow-covered and snow-free areas. Precipitation storage as snow in winter and spring can critically modulate hydrological droughts in summer. Concerning streamflow, droughts are often related to the presence or absence of snow in the preceding winter, whereas winter droughts can occur despite large amounts of precipitation falling as snow [62]. One extension of the SPI is the Standardized Snowmelt and Rain Index (SMRI). This accounts for the impact of rain and snowmelt deficits on streamflow. The SMRI has been found to be a valuable complementary index for characterizing streamflow droughts in catchments with a significant snowmelt component in runoff generation [52]. When the snow/precipitation ratio decreases, the SMRI approaches the SPEI. However, the difference between SPEI and SMRI increases with the increasing impact of snow cover on streamflow for the entire and dry periods only [52]. Moreover, meteorological drought indices that include evaporation or snowmelt can be better correlated with streamflow [63].

The water level of Lake Urmia also experiences monthly and seasonal variations, primarily determined by snowmelt [24]. Thus, depending on the snowmelt in the surrounding mountains, the Urmia water level peaks in May-June (precipitation peaks from October to May) and drops to a minimum in October to December due to the lack of snowmelt. Overall, monthly fluctuations in lake water level can be up to nearly $0.6 \mathrm{~m}$ [24]. Urmia Lake started drying out about twenty years ago, and the lake level has declined by more than eight meters during this period. Since reaching its highest level in 1995 (1278.48 m), the water level has decreased annually on average by $40 \mathrm{~cm}$ over the last two decades. In September 2015, it reached the lowest level, and southern parts of the lake dried out. Indeed, the whole lake is a moderately shallow water body (about $6 \mathrm{~m}$ deep on average) Figure 1 [64].

The main objective of the present study is to better understand drought events in the ULB by focusing on SMRI in addition to the SPI and SPEI indices. Use is made of the SPEI index in order to assess the impact of rising temperatures. The ERA 5 dataset has been used for drought indices to provide for a higher density of meteorological data and allow for a more elongated data period. The paper is organized as follows: Section 2 introduces the materials and methods. Sections $3-5$ contain results, discussion, and conclusions, respectively. 


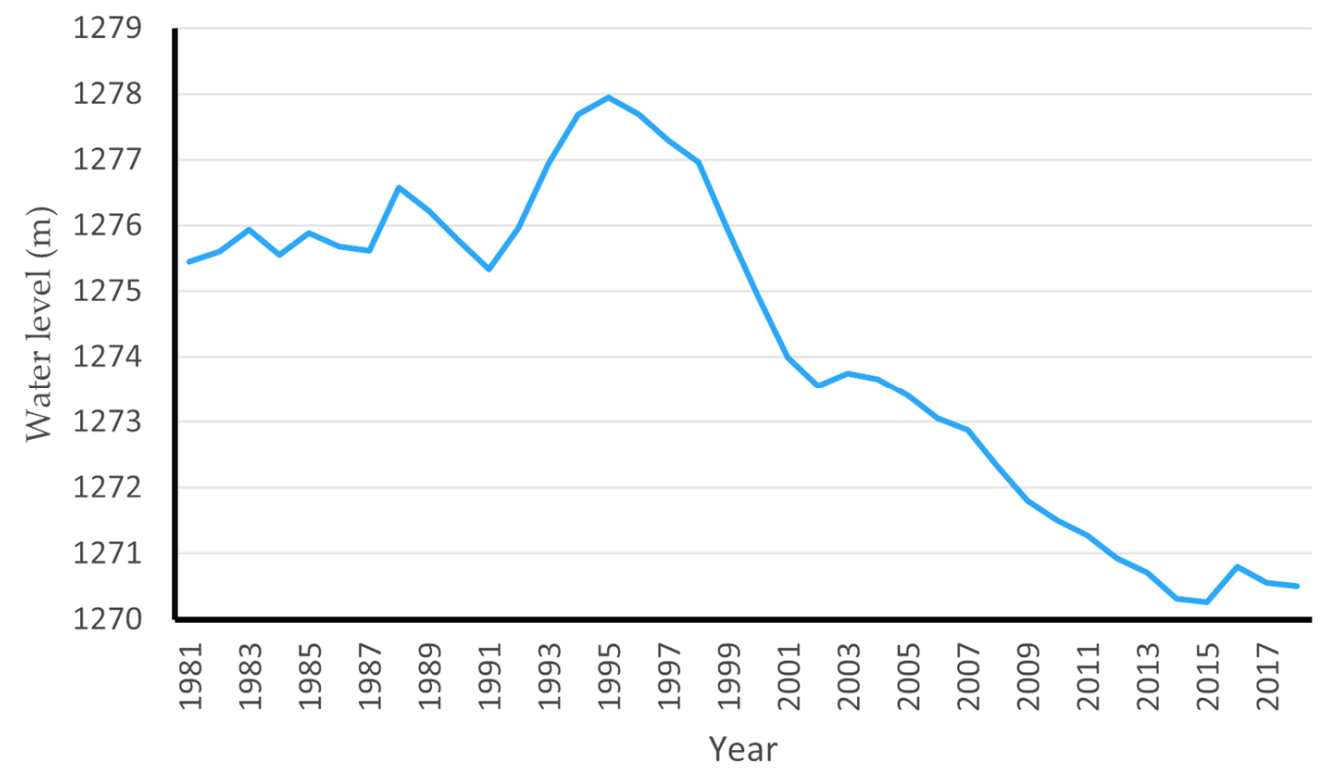

Figure 1. Measured water level (m) of Urmia Lake since 1981.

\section{Materials and Methods}

\subsection{Lake Urmia Catchment}

Located in the mountainous region of north-western Iran, Lake Urmia (Figure 2) and its catchment basin cover an area of approximately 52,000 km². Lake Urmia, the world's second-largest saline lake, covers about $5000 \mathrm{~km}^{2}$ and belongs to Iran's Western Azerbaijan and Eastern Azerbaijan provinces.

The specific geology of this area, the high amount of evaporation, and the constant solute aggregation result in highly salty soils. The lake is surrounded by some freshwater wetlands, which are of ecological importance. The Mediterranean climate of the Urmia Basin is influenced by the surrounding high mountains and is characterized by cold winters and relatively temperate summers. The basin's long-term average temperatures are $0.2{ }^{\circ} \mathrm{C}$ in winter (December-January-February) and $23.9^{\circ} \mathrm{C}$ in summer (June-July-August), while the average annual temperature is $12.3^{\circ} \mathrm{C}$. July and August are the warmest, and January and February are the coldest months of the year. Long-term average evaporation (for the 35-year record from 1966 to 2000) from Lake Urmia is $1373.7 \mathrm{~mm} \mathrm{yr}^{-1}$, and the highest evaporation has been observed in July and August. Precipitation in the Urmia basin is estimated to be $302.8 \mathrm{~mm} \mathrm{yr}^{-1}$, mainly falling in the period from October to March (with the highest amount in spring), during which the region is affected by the Rossby-forced advection of the Mediterranean, and sometimes, the Siberian air masses. In contrast, precipitation is comparatively low from June to September due to the dominance of upper-level ridges of high pressures. Annual evaporation is much higher than annual precipitation, suggesting that the lake is suffering from a water deficit [24].

\subsection{ERA5 Reanalysis Data}

The European Center for Medium-range Weather Forecast (ECMWF) has released the ECMWF Reanalysis v5 (ERA5) dataset as part of the Copernicus Climate Change Services. The dataset uses a spatial resolution of $31 \mathrm{~km}$, covering the period from 1979 onwards [65]. We used ERA5 monthly precipitation and 2-m air temperature data with a $0.25^{\circ}$ grid spacing for 1981-2018. ERA5 datasets were compared with gauge observations over the Karun basin in southwestern Iran and were found to be quite accurate [66]. In contrast, ERA-Interim, The Climate Forecast System Reanalysis (CFSR), and the Japanese 55-year Reanalysis (JRA55) interpolated datasets show larger underestimations relative to observations [67]. In addition, the performance of ERA5 data is generally more consistent across different climate variables. In the absence of observational precipitation data, ERA5 and ERA-Interim are 
the best choices for data covering the Sistan and Baluchestan provinces, one of Iran's poorly gauged areas for rain [67]. The ERA5 data has also been validated against observations from the Ardabil province near the ULB [68]. It was found that, after correcting for bias, the ERA 5 daily and monthly precipitation data was quite adequate, particularly given the data scarcity prevailing in the region. The ERA5 precipitation dataset was compared to observational datasets from meteorological stations in nine different precipitation zones of Iran for the period 2000-2018. After correcting for bias, ERA5 precipitation reanalysis datasets were found to be a very promising substitute for weather station data [69].
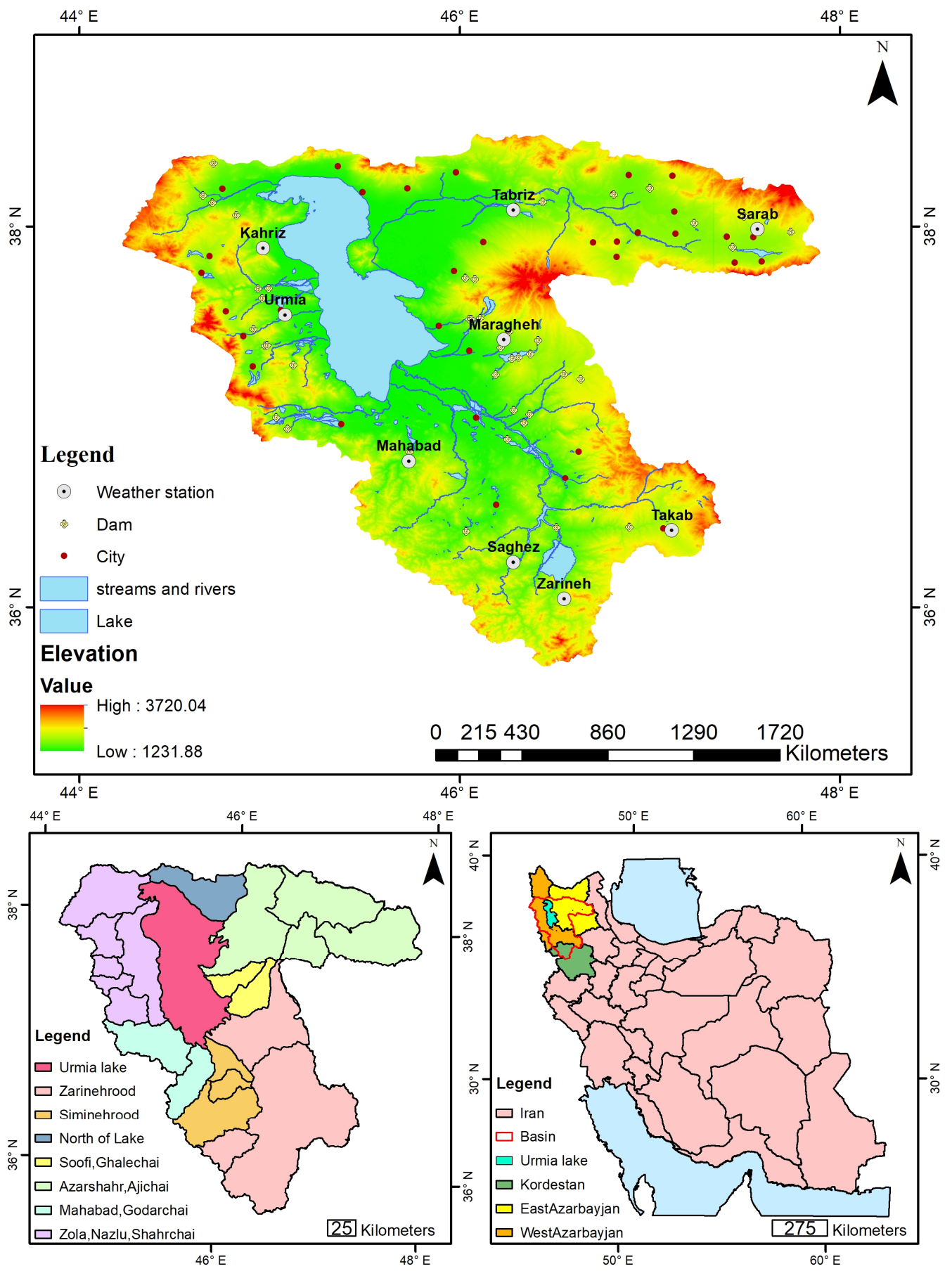

Figure 2. Geographical location of Lake Urmia. 


\subsection{Observational Data}

Precipitation and temperature data was obtained from the Iran Meteorological Organization for nine synoptic weather stations from 1995-2018. Table 1 and Figure 2 show the geographical location of the weather stations in the basin. The synoptic stations, geographically dispersed around the Urmia Lake basin, were selected to represent the conditions prevailing among the mixture of plain and mountainous locations.

Table 1. Geographical characteristics of stations in the basin.

\begin{tabular}{ccccc}
\hline Station & Lon. & Lat. & Altitude $(\mathbf{m})$ & Period of Data \\
\hline Saghez & 46.28 & 36.23 & 1522 & $1995-2018$ \\
Takab & 47.12 & 36.40 & 1817 & $1995-2018$ \\
Mahabad & 45.73 & 36.77 & 1352 & $1995-2018$ \\
Maragheh & 46.23 & 37.40 & 1344 & $1995-2018$ \\
Urmia & 45.08 & 37.53 & 1336 & $1995-2018$ \\
Sarab & 47.57 & 37.98 & 1682 & $1995-2018$ \\
Kahriz & 44.97 & 37.88 & 1336 & $1995-2018$ \\
Tabriz & 46.28 & 38.08 & 1364 & $1995-2018$ \\
Zarineh & 46.55 & 36.04 & 2142 & $1995-2018$ \\
\hline
\end{tabular}

\subsection{Drought Indices}

The SPI, SPEI, and SMRI drought indices were generated using the R software package [70]. This is a free software package for statistical computation and graphics.

\subsubsection{Standardized Precipitation Index (SPI)}

The SPI is designed to assess drought conditions based on the probability distribution of long-term precipitation using the gamma distribution [39]. Precipitation data is transformed into normalized values. The SPI is given as the number of standard deviations by which the observed precipitation deviates from the long-term mean for a normally distributed random variable. It can thus be used to define and compare drought conditions in different areas. The index gives a good and reliable estimate of drought magnitude, severity, and spatial extent. When precipitation is above the long-term mean value, the SPI is positive, and if precipitation falls below the long term, the SPI is negative. Unlike other drought indices, SPI is relatively easy to use because it only requires a single input data series of long-term precipitation [71]. As it is based on normalized data, the SPI is spatially invariant, and droughts can be assessed in different regions [72]. The index is calculated as follows:

$$
\mathrm{SPI}=\frac{x_{i}-\bar{x}}{\sigma}
$$

where $x_{i}$ is the precipitation of the selected period during the year $i, x$ is the long-term mean precipitation and $\sigma$ is the standard deviation for the selected period.

\subsubsection{Standardized Precipitation Evaporation Index (SPEI)}

SPEI is calculated based on the non-exceedance probability of the differences between precipitation and potential evapotranspiration (PET), adjusted using a three-parameter logistic distribution which accounts for common negative values [51,73]. SPEI uses a threeparameter distribution to capture the deficit values since it is most likely that the moisture deficit can be damaging in arid and semi-arid areas. For two-parameter distributions as used in SPI, the variable $\mathrm{x}$ has a lower boundary of zero $(0<x<\infty)$, meaning that $x$ can only take positive values. In contrast, for the three-parameter distributions used in SPEI, $x$ can take values in the range $(\gamma<x<\infty)$, implying that $x$ can also take negative values; $\gamma$ is the parameter of origin of the distribution [51]. Use of the log-logistic distribution is thus recommended for SPEI since it provides a better fit for extreme negative values [74]. The SPEI is obtained by normalizing the water balance into the log-logistic probability distribution. For the purposes of the present study, PET is estimated using the Thornthwaite 
method [75]. The difference $\left(D_{i}\right)$ between precipitation $(P)$ and PET for the month $(i)$ is given by:

$$
D_{i}=P_{i}-\mathrm{PET}_{i}
$$

The calculated $D$ values are aggregated at different time scales as follows:

$$
D_{n}^{k}=\sum_{n=0}^{k-1} P_{n-1}-(\mathrm{PET})_{n-1}
$$

where $k$ is the timescale (months) of the aggregation and $n$ is the calculation month. The probability density function of a log-logistic distribution is given as:

$$
f(x)=\frac{\beta}{\alpha}\left(\frac{x-y}{\alpha}\right)^{\beta-1}\left(1+\left(\frac{x-y}{\alpha}\right)^{\beta}\right)^{-2}
$$

where $\alpha, \beta$ and $\gamma$ are scale, shape, and origin parameters respectively for $\gamma>D<\infty$. The probability distribution function for the $D$ series is then given as:

$$
D=\left[1+(\alpha / x-y)^{\beta}\right]^{-1}
$$

With $f(x)$ the SPEI can be obtained as the standardized values of $\mathrm{F}(\mathrm{x})$ according to the empirical method of [76]: where

$$
\mathrm{SPEI}=W-\frac{C_{0}+C_{1} W+C_{2} W^{2}}{1+d_{1} W+d_{2} W^{2}+d_{3} W^{3}}
$$

And

$$
W=\sqrt{-2 \ln (P)}
$$

For

$$
P \leq 0.5
$$

$P$ is the probability of exceeding a determined $D_{i}$ value and is given as $P=1-f(x)$ while the constants are:

$C_{0}=2.515517, C_{1}=0.802853, C_{2}=0.010328, d_{1}=1.432788, d_{2}=0.189269, d_{3}=0.001308$.

The probability distribution function is given by; $F(x)=1[1+\exp (-y)]^{-1}$. The $F(x)$ values were then transformed to a normal variable by means of the above approximation by [77].

Hosking and Wallis [78] showed that the Di (P-ET0) distribution consistently produces the best goodness of fit to the generalized logistic (GLO) functions across all accumulation. The GLO is given by the above probability density function.

Since SPEI is a standardized variable, it can be used to compare droughts over different spatial and temporal scales. As with SPI values, negative SPEI values define drought conditions, and its accumulated values define the intensity, severity, magnitude, and duration of drought [79].

\subsection{Standardized Snow Melt and Rain Index (SMRI)}

The SMRI is based on precipitation and snowmelt minus snow accumulation. Snow accumulation, expressed as the amount of liquid water accumulated as snow, occurs when the mean temperature is smaller than a threshold temperature of $1^{\circ} \mathrm{C}$. In contrast, snowmelt, expressed as the amount of liquid water melted, is calculated with a simple temperature index model using a melt factor of $3 \mathrm{~mm} /{ }^{\circ} \mathrm{C}$-day (similar to [80]). The difference values, 
where $P_{i}$ is precipitation, PET is potential evaporation, $S A$ is snow accumulation, and $S M$ is snowmelt [52,81], lead to the following SMRI equation:

$$
D_{i}=P_{i}-\mathrm{PET}_{i}+\sum_{i=1}^{\infty} S M-\sum_{i=1}^{\infty} S A
$$

\subsection{Drought Characteristics-Duration, Severity, Frequency}

Once a drought event was identified using the SPI, SPEI and SMRI indices, the drought starts and ends, drought duration (DD), and drought severity (DS) were derived from index data. DD is equal to the number of months between the starting month (included) and ending month (not included). DS is the absolute value of the integral area between line indices and the horizontal axis (SPI $=0, \mathrm{SPEI}=0$, and $\mathrm{SMRI}=0)$ from the beginning and ending month of drought. Drought frequency (DF) is represented by the number of events per 38 years (the whole period). Table 2 gives an overview of indices values for three drought categories. Drought begins when the index value is less than or equal to -1 , and it ends when values become positive [39,82-84]. Figure 3 shows the drought characteristics using the run theory for a given threshold level. In runs theory, drought intensity is the average value of a drought parameter below the threshold level, which is measured as the drought severity divided by the duration [85]

Table 2. Drought classification scheme [39].

\begin{tabular}{cc}
\hline Value & Drought Category \\
\hline-1 to -1.49 & Moderate dryness \\
-1.5 to -1.99 & Severe dryness \\
$<-2$ & Extreme dryness \\
\hline
\end{tabular}



Figure 3. Drought characteristics using the run theory for a given threshold level [85].

The duration $(D)$ of drought is the period in which the SPEI/SPI/SMRI value is continuously negative. It starts when the indices values are equal to -1 and ends when values become positive. The drought severity $(S)$ is the cumulated index values within the drought duration, which is defined by:

$$
S=-\sum_{i=1}^{D} \text { Indexes }_{i}
$$

\subsection{Relative Operative Characteristics (ROC) and Brier Skill Score (BSS)}

The ROC curve is a performance measurement for classification problems at various threshold settings. The ROC method is a useful tool for assessing how well the ERA5-based drought classes can capture observational-based drought classes. It identifies how capable 
the model is of distinguishing between simulated classes (true positive, false positive, true negative, false negative). The ROC plots the True Positive Rate (TPR) against the False Positive Rate (FPR), where TPR is shown on the y-axis and FPR is shown on the x-axis. The rates are calculated as shown below [86]:

$$
\begin{aligned}
& T P R=\frac{T P}{T P+F N} \\
& F P R=\frac{F P}{F P+T N}
\end{aligned}
$$

where,

TP: True Positives, are correct captures of drought classes.

FP: False Positives, are incorrect capture of drought classes.

$T N$ : True Negatives, represent the capture of non-occurrence of specific drought classes $F N$ : False Negatives, represent the failure to capture the occurrence of specific drought classes.

The larger the Area Under Curve (AUC, which is the area under the ROC curve), the better the model simulates the classes (a perfect simulation is achieved when AUC $=1$ ). For a model equivalent to random guessing, the AUC value is equal to 0.5. Table 3 shows a contingency table for distinguishing drought classes in terms of ERA5 and observational data.

Table 3. Contingency table for analysis of drought event detection by ERA5 data.

\begin{tabular}{cccc}
\hline \multicolumn{2}{c}{$\begin{array}{c}\text { Drought Classes } \\
\text { (Wet, Normal, and Dry) }\end{array}$} & ERA5 \\
\cline { 2 - 4 } & Yes & TP & No \\
\hline \multirow{2}{*}{ ERA5 Simulated } & No & FN & FP \\
& & & TN \\
\hline
\end{tabular}

\section{Results}

\subsection{The Ability of ERA5 to Capture Drought Characterization over ULB}

Figure 4 shows the basin's mean annual precipitation and temperature during 19952018 using ERA5 gridded (red line) and observational data (blue line). The basin's mean precipitation and temperature for the ERA5 and observational data are calculated using the mean gridded and Thissen methods, respectively. The correlation, RMSE, and bias of ERA5 precipitation and temperature with respect to observational data are shown in Tables 4 and 5. From Figure 4 and Table 4, it can be concluded that ERA5 data, after simple bias correction, can reasonably simulate the observed precipitation and temperature of the basin, specially over areas lacking adequate data. (Figure 4).



(a)

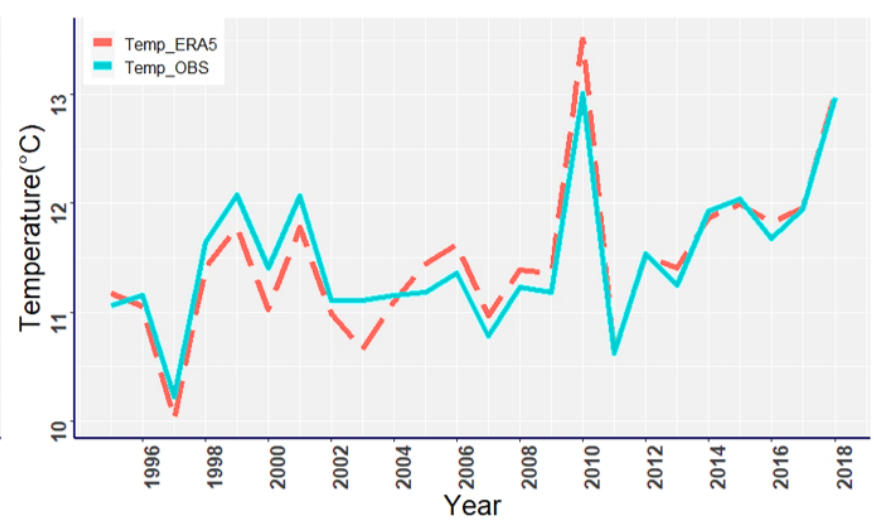

(b)

Figure 4. Comparison of observed (blue line) and ERA5 (red line) precipitation (a) and temperature (b) of the ULB. 
Table 4. Correlation, bias and RMSE of ERA5 data comparing to observational data over Urmia Lake basin.

\begin{tabular}{cccc}
\hline & Correlation & Bias & RMSE \\
\hline Precipitation $(\mathrm{mm})$ & 0.389 & 0.112 & 0.205 \\
Temperature $\left({ }^{\circ} \mathrm{C}\right)$ & 0.911 & 1.229 & 1.25 \\
\hline
\end{tabular}

Table 5. Correlation and RMSE of ERA5 against observational indices over Urmia Lake basin.

\begin{tabular}{ccc}
\hline Indices & Correlation & RMSE \\
\hline SPI3 & 0.458 & 0.356 \\
SPEI3 & 0.759 & 0.269 \\
SMRI3 & 0.628 & 0.348 \\
SPI6 & 0.638 & 0.438 \\
SPEI6 & 0.815 & 0.3 \\
SMRI6 & 0.632 & 0.445 \\
SPI12 & 0.627 & 0.524 \\
SPEI12 & 0.829 & 0.346 \\
SMRI12 & 0.626 & 0.5772 \\
\hline
\end{tabular}

As ULB weather stations data are often inadequate, we used ERA5 reanalysis data (thus providing us with full spatial coverage) to analyze the basin's drought conditions. In order to quantify systematic differences between the two data sets, the SPI, SPEI, and SMRI drought classes computed from station observations were compared with relevant ERA5- derived indices (for 3-, 6- and 12-monthly accumulated values). The ROC curves and Brier Skill Score (BSS) were then used to evaluate how well the ERA5 dataset captures different drought classes over the basin compared to measurements at meteorological stations (Table 6).

Table 6. Brier Skill Score (BSS) of ERA5 data representing drought over ULB using SPI, SPEI, SMRI.

\begin{tabular}{cccccccccc}
\hline \multirow{2}{*}{ Run } & \multicolumn{3}{c}{ SPI } & \multicolumn{3}{c}{ SPEI } & \multicolumn{3}{c}{ SMRI } \\
\cline { 2 - 10 } & Dry & Normal & Wet & Dry & Normal & Wet & Dry & Normal & Wet \\
\hline $3-\mathrm{m}$ & 0.96 & 0.83 & 0.69 & 0.89 & 0.84 & 0.91 & 0.88 & 0.87 & 0.87 \\
6-m & 0.96 & 0.83 & 0.69 & 0.93 & 0.96 & 0.93 & 0.94 & 0.87 & 0.84 \\
$12-\mathrm{m}$ & 0.96 & 0.83 & 0.70 & 0.89 & 0.84 & 0.92 & 0.91 & 0.94 & 0.86 \\
\hline
\end{tabular}

The BSS scores (Table 6) show high consistency between ERA5 and observational data for SPI, SPEI, and SMRI. To further illustrate the consistency of the drought indices from ERA5 data, we also analyzed ROC curves. The ROC curves are close to each other for the dry, wet, and normal SPEI category on 12-months running, with an average BSS score of $0.9-1$ showing good to excellent consistency between ERA5 and observations over ULB. In SPI, the ROC curves for dry and normal events with AUC of 0.83-0.96 show excellent consistency of ERA5 data with observation, especially in the simulation of dry cases. The amount of AUC (BSS) for wet events is 0.70 . Figure 5 shows that among the three indicators on a 12-month scale, the highest correlation exists between the SMRI drought index obtained from ERA5 and observation data. In addition, as can be seen for all drought indices, dry conditions are better identified by ERA5 data than are other conditions. 

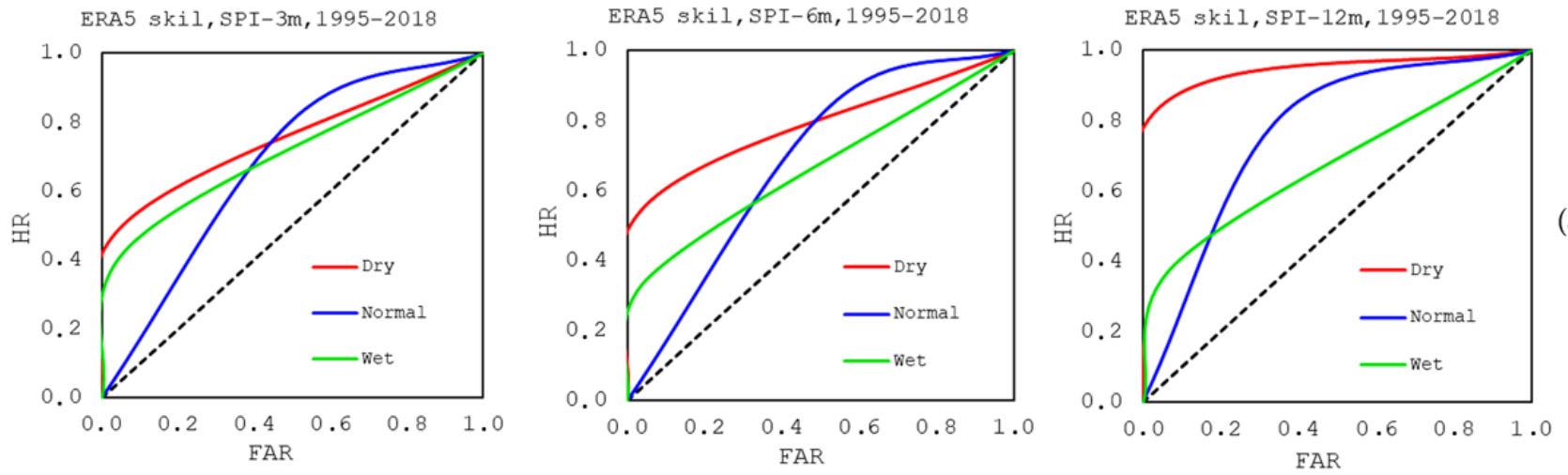

(a)
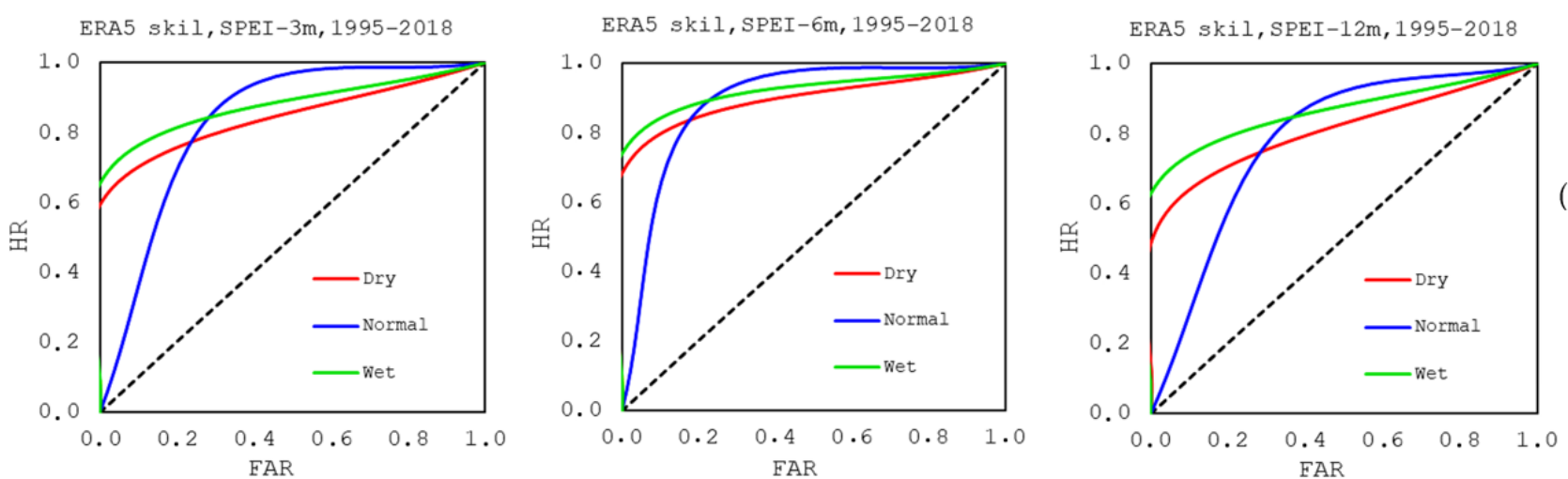

(b)
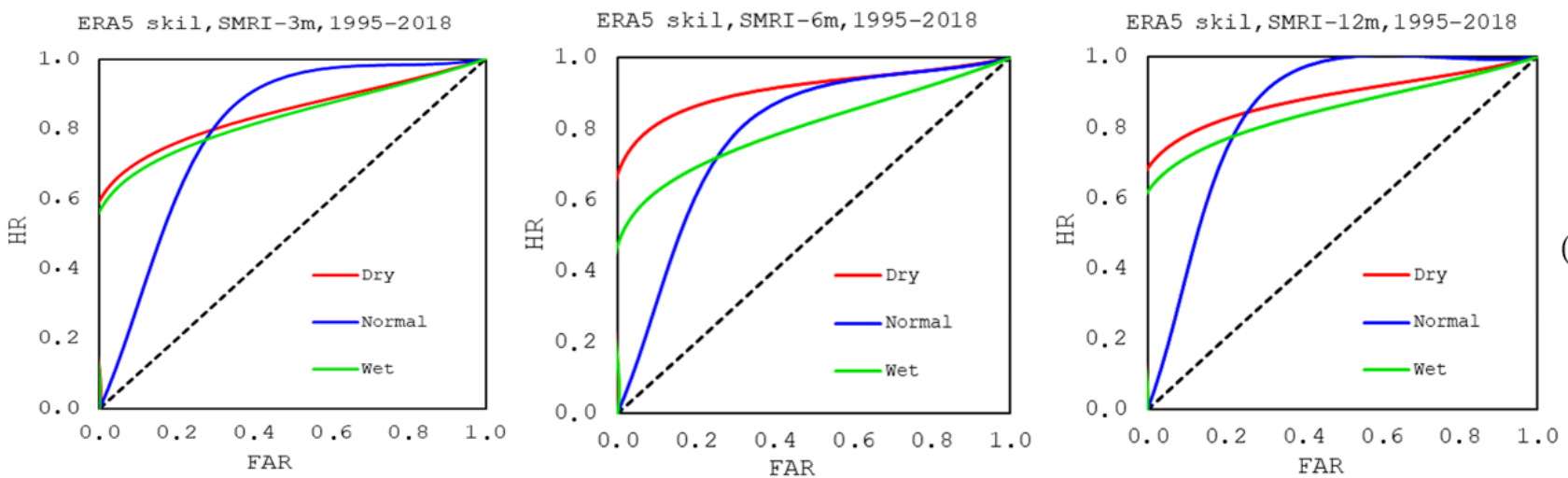

(c)

Figure 5. ROC curve for SPI (a), SPEI (b), SMRI (c) for three classes of dry, wet and normal drought conditions over ULB.

\subsection{Temporal Evolution of the SPI, SPEI, and SMRI in ULB}

To quantify the temporal evolution of SPI, SPEI, and SMRI for the ULB and to check the robustness of ERA5 results we compared the basin-wide indices for observational data with ERA5 over the period 1995-2018. This is shown in Figure 6. There is a general consistency between both input data sets for SPI (Figure 6a), SPEI (Figure 6b), and SMRI (Figure 6c). However, SPI and SPEI drought indices differ slightly depending on the time interval, especially at 3-, 6- and 12-months intervals. In recent decades, droughts indicated by SPEI have been more severe than those of SPI, mainly due to an increase in temperature and the related higher evapotranspiration rate. On the other hand, SMRI index values have also been rising, reflecting the conversion of solid precipitation to rain, the decline in snow storage in winter, and the relatively low amount of snowmelt during late spring to early summer. Figure 6 and Table 5 also imply that, as the time scale of the drought index increases from 3 months to 12 months, the correlation between ERA5 and observation data increases. 


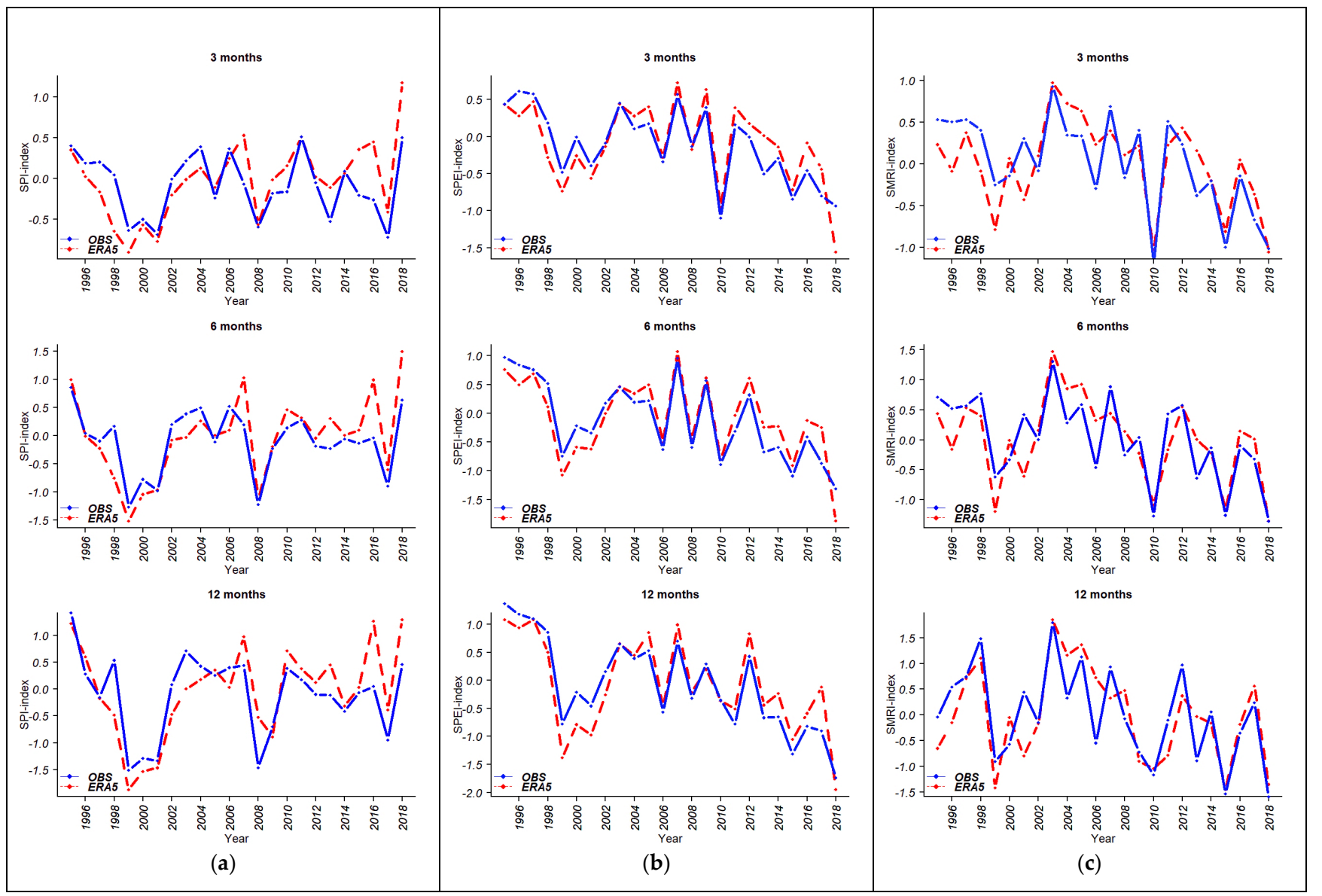

Figure 6. Time series showing 3-, 6- and 12- months accumulated values of SPI (a), SPEI (b) and SMRI (c) indices based on ERA5 (red) and observation (blue).

Regarding the seasonal distribution of the three drought indicators (averaged over the Urmia Lake Basin for the period 1995-2018) our analyses show that more severe droughts of the SPEI type (i.e., those induced by changes in precipitation and evapotranspiration) developed in most months, whereas for SPI-type droughts (precipitation driven) occurrence tends to be limited to late spring and summer (i.e., to the warmer months of the year). For SMRI-type droughts, severe droughts occurred from summer until to the end of fall) Figure 7.

In addition to seasonal variability, long-term variations and changes in SPI, SPEI, and SMRI data are also of interest, particularly with respect to the impact of climate change. On the one hand, drought frequencies and intensities differ, with differences decreasing with increasing drought timescale. The differences between the SPI and the other two indices have been increasing in recent years. This is particularly obvious from 2001 onwards. In fact, while there are a few moderate to extreme (index $\leq-1$ ) droughts of SPI type from 2001 onwards, there is a clear increasing trend in extreme SPEI and SMRI type droughts (Figure 8). It is also clear that snowmelt-type droughts (SMRI) have become more common in recent years-especially since 2010 - than other types of droughts (SPI and SPEI). This follows from the rising basin temperatures over the same period, which has led to a decrease in solid precipitation and a decreased snowmelt, and thus to an increase in the SMRI drought sequence. As a result of the associated rise in evapotranspiration, the SPEI type droughts are also affected by the basin temperature increase (Figure 8). 


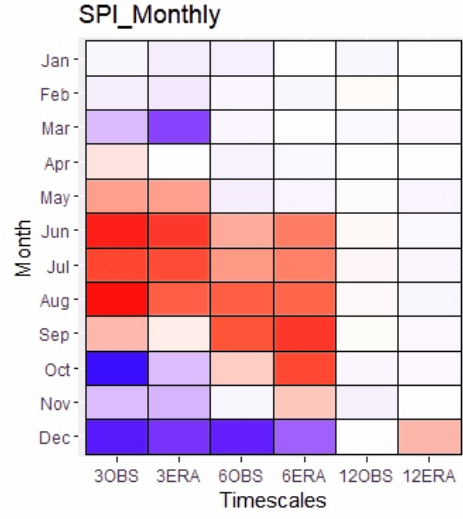

(a)

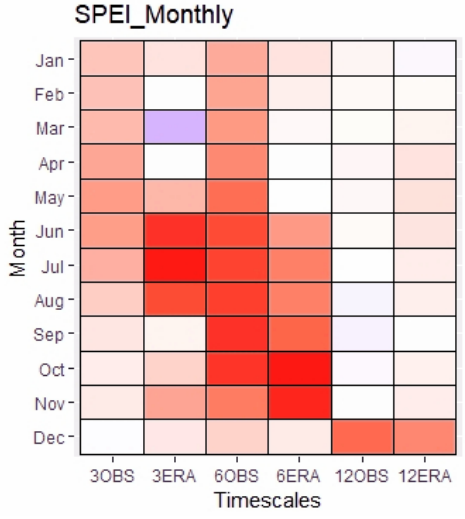

(b)
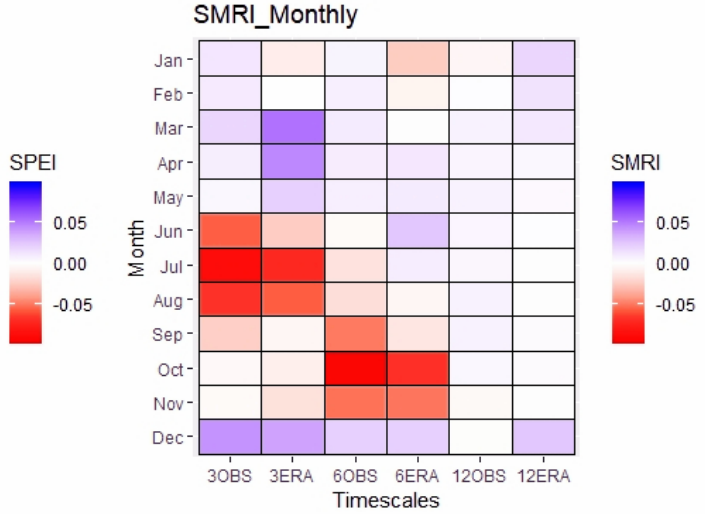

(c)

Figure 7. Monthly distribution of Indices (a) SPI, (b) SPEI, (c) SMRI.
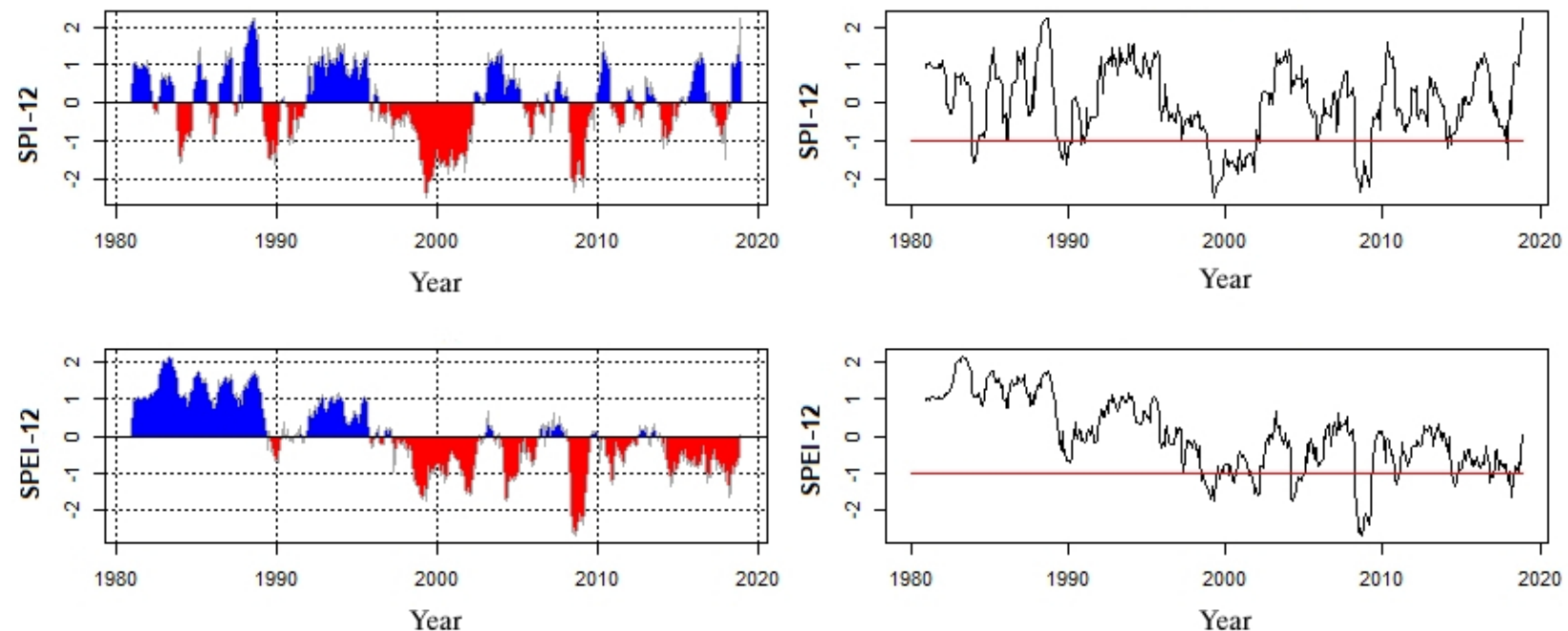

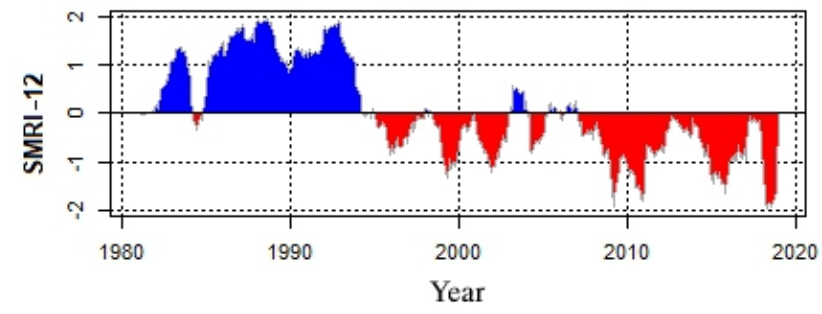

(a)



(b)

Figure 8. Time series of SPI, SPEI and SMRI indices of ULB over 1981-2018 (a) and their values under the threshold of $-1(\mathbf{b})$.

\subsection{Drought Characteristics}

The identified droughts were further characterized in terms of their severity, duration, and frequency at various timescales by analyzing their spatial distributions. For this purpose, we focused on specific dry and wet events derived from monthly SPI, SPEI, and SMRI data for the 38-year period from 1981 to 2018. In order to identify drought hotspots, we focused particularly on the years with moderate to extreme drought. Based on Table 2, threshold values related to moderate, severe, and extreme drought (index $\leq-1$ ) were chosen to assess the drought characteristics using the three drought indices. 


\subsubsection{Drought Duration}

Drought duration data in the ULB show a clear increase in snowmelt-driven droughts (SMRI) over the last years of the study period, particularly in 2010, 2015, and 2018. Similarly, drought duration for precipitation-driven droughts (SPI) were recorded in 1999, 2000, and 2001. Another noteworthy point on the SMRI droughts is that before 1995, no snowmelt drought occurred on any of the 3 to 12 -month scales, indicating that there was not snowmelt in the water balance from 1981 to 1994 . The decrease in snow precipitation in the basin then becomes noticeable and is clearly captured by the SMRI after 1995. The changes in the SPEI drought index are similar to those in the SMRI. This is no great surprise as the increase in ULB air temperatures and associated rise in evapotranspiration also began to play an ever-increasing role in drought events. Consequently, SMRI and SPEI indices are now more suitable for capturing drought conditions in the basin than the SPI index. Figure 9 also shows that based on SMRI data the most prolonged droughts occurred in the last decade in 2010, 2015, and 2018 (in particular for the 12-months timescale). This corresponds to other sources on drought information. The lake surface area diminished from 5650 square kilometers in 1998 to about 2005 square kilometers in 2010 [87]. The lowest annual surface discharge to the lake, recorded in 2015, was only $0.5 \mathrm{~km}^{3}$ [88]. During their fieldwork in October 2018, previous research noticed that, especially on the eastern side of the lake, many people were complaining about the increasing occurrence of respiratory diseases as a result of a lake salt storm [89]. According to the SPI index, the 2015 and 2018 ULB droughts are classified as light drought and slightly wet, respectively. However, the SPEI index reveals large differences with respect to the impact of temperature, and the two droughts are classified as severe and moderate, respectively. According to the Ministry of Energy [90], the SPEI drought index results are consistent with the actual drought in the basin.



(a)

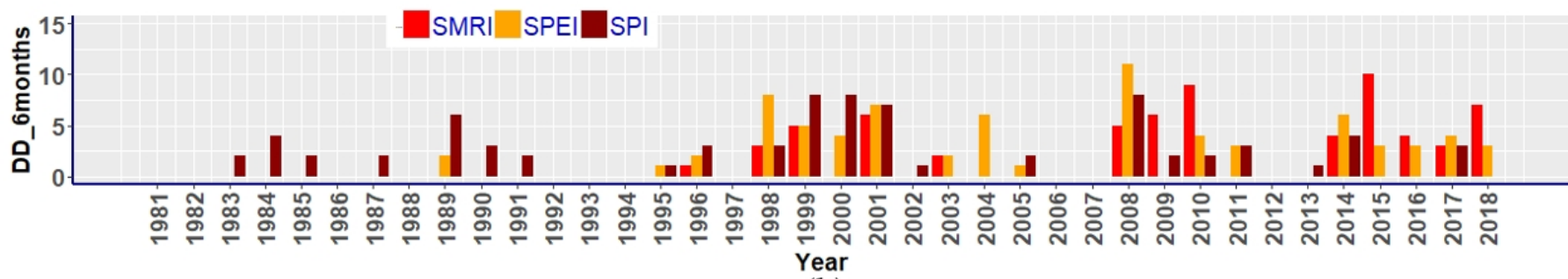

(b)

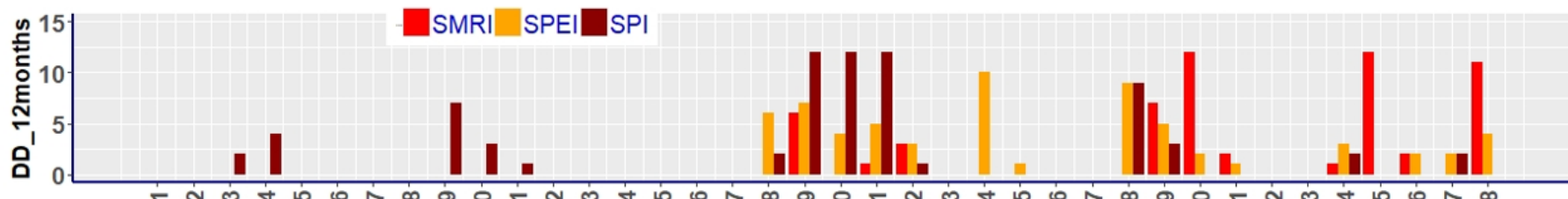

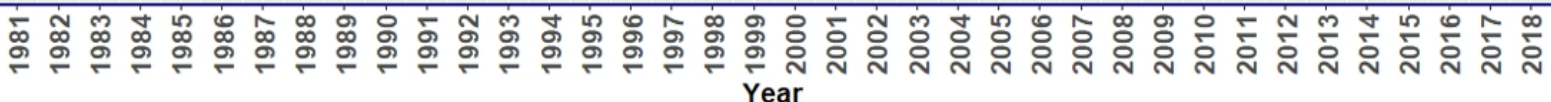

(c)

Figure 9. Drought Duration (DD) over ULB using SPI, SPEI and SMRI indices,1981 to 2018. (a) 3_months, (b) 6_months and (c) 12_ months. 


\subsubsection{Drought Severity}

Developments in the time series of drought severity (Figure 10) are similar to those found for drought duration. From the beginning of the study period up to 1996, drought severity according to the SMRI index is almost zero. This indicates that before 1996, the Urmia Lake Basin did not face the challenge of snowmelt drought. The first severe SMRI drought event occurred around 1995/1996. From 1996 onward, however, the severity of snowmelt drought in the basin has increased. As was the case for drought duration, the most severe snowmelt droughts occurred in the more recent years, i.e., 2010, 2015, and 2018.The severity levels using SPEI and SPI indices were clearly less marked than those indicated by the SMRI data. Again, these results indicate that snowmelt drought is highly relevant for ULB, and droughts identified by SMRI give a more realistic picture of ULB droughts than the other two indicators. As can be seen in Figure 11, there is a clear correspondence between ULB drought severity and drought duration. The more severe the drought, the longer the drought duration. Use of the Palmer Drought Severity Index has also shown that while, on average, drought episodes have hit the Urmia Lake Basin every five years and most of them reached severe levels, the more recent droughts have also become more intense and of longer duration [25].

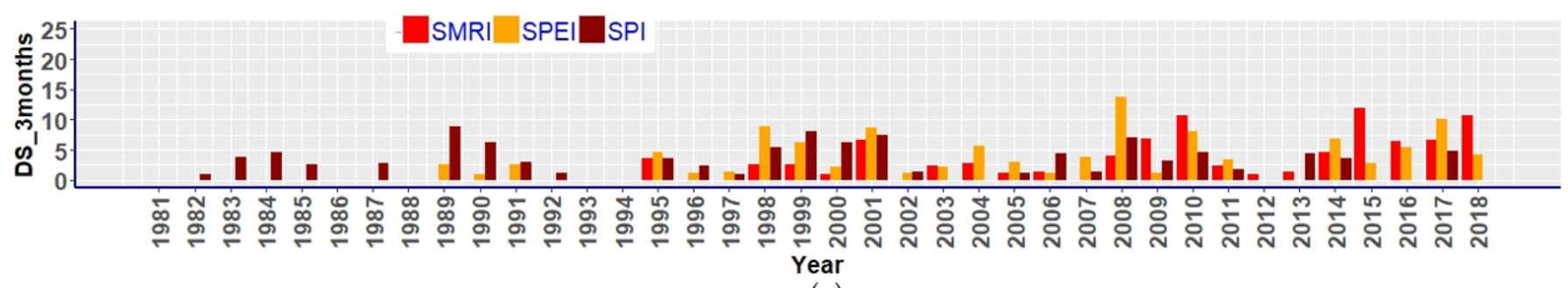

(a)

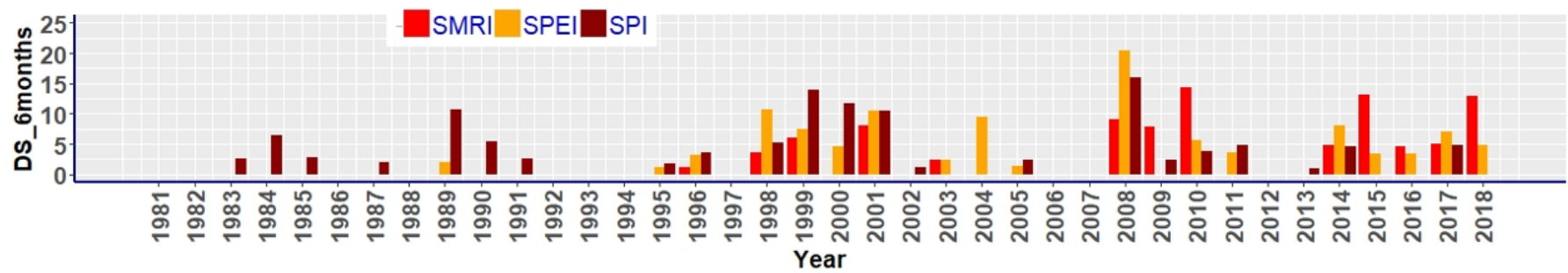

(b)

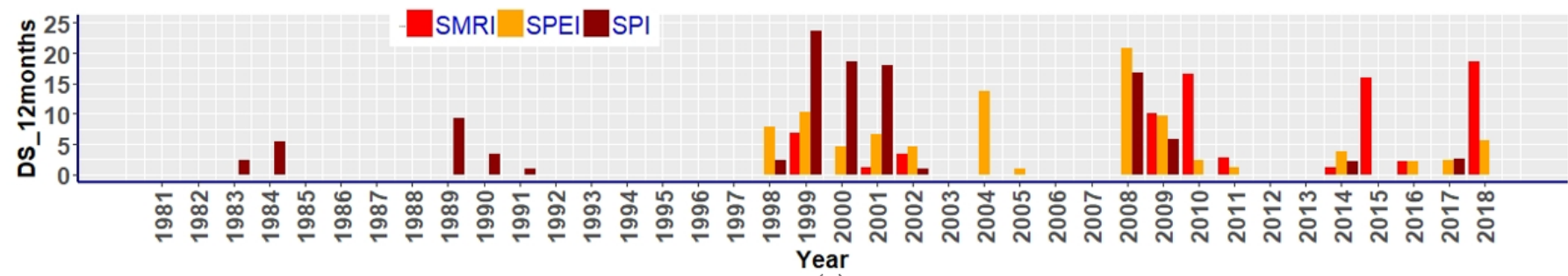

(c)

Figure 10. Drought Severity (DS) over ULB using SPI, SPEI and SMRI indices,1981 to 2018. (a) 3_months, (b) 6_months and (c) 12_ months. 

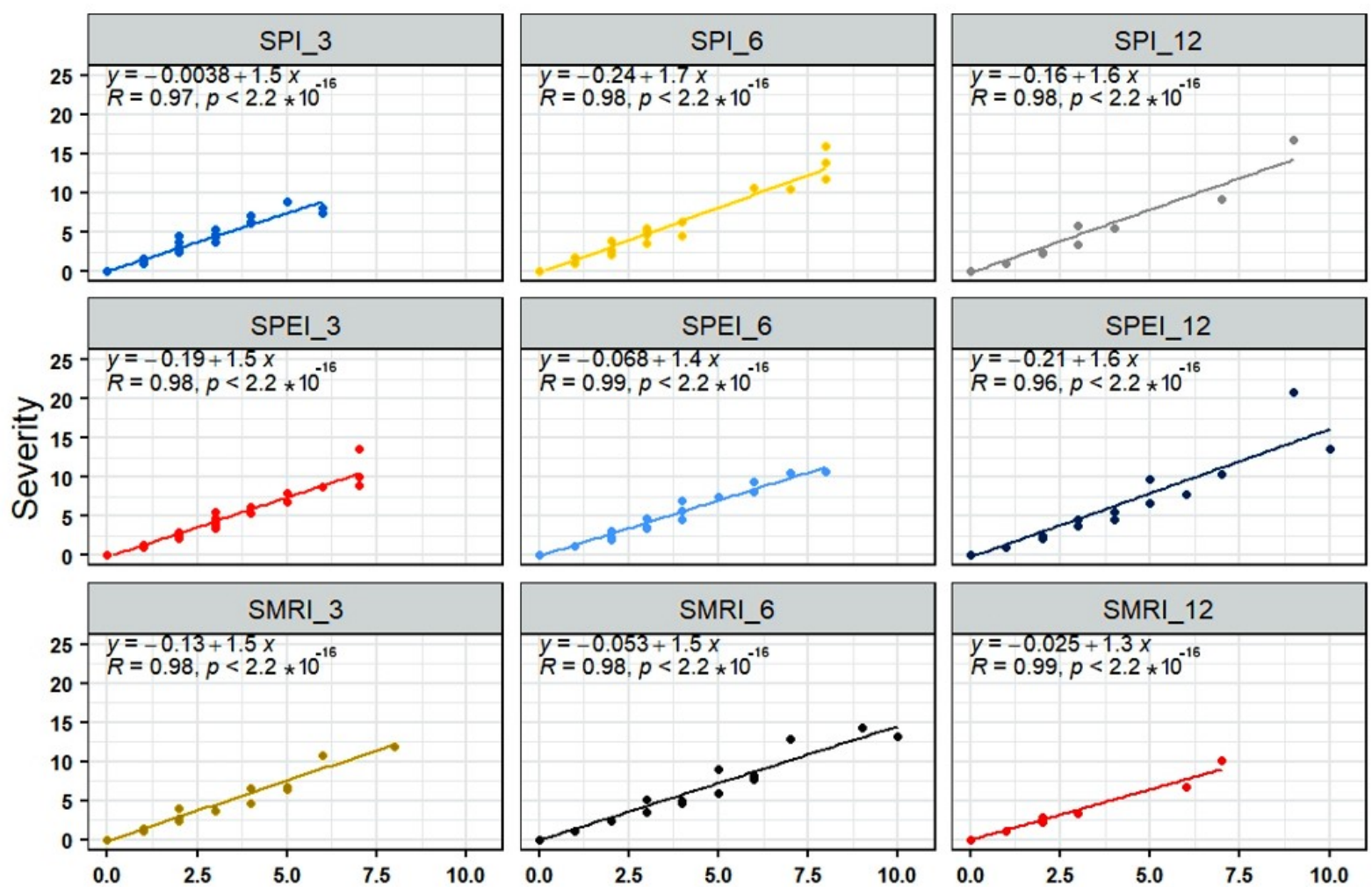

(a)



(b)
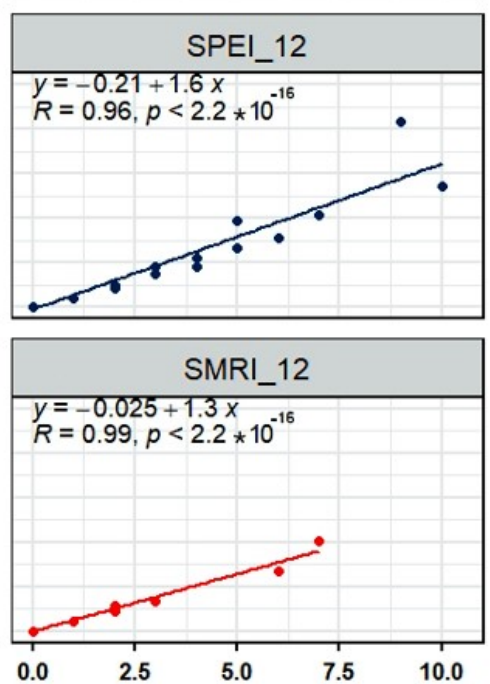

(c)
Index

$\rightarrow$ SPI_3

* SPI6

$\rightarrow$ SPI 12

$\rightarrow$ SPË 3

- SPEI_6

- SPEI 12

$\rightarrow$ SMRI_3

$\rightarrow$ SMRI 6

$\rightarrow$ SMRI_12

Figure 11. Aligning drought severity with its duration during period of 1981-2018: (a) 3_months, (b) 6_months and (c) 12_months.

\subsubsection{Spatial Distribution of Drought Severity}

Besides the temporal changes in drought events, the spatial patterns of drought events within the study region are also relevant for drought management. Figure 12 maps drought severity and shows some obvious drought hotspots. The spatial distribution of drought conditions in selected years with moderate and severe/extreme droughts were mapped for each index in order to evaluate spatial characteristics. The year 2001 was selected as the moderate year in the SPI index. The figure shows that the riverbed was most affected by severe droughts, but in 1999, which was considered the most severe year, not only the river but also the southern parts of the basin exhibit extreme drought. In evaluating SPEI spatial severity, 2009 and 2004 were selected as moderate and severe years, respectively. According to the SPI index, drought conditions were largely restricted to the riverbed. In 2009, the northeastern parts of the basin were subject to extreme drought. The SMRI index shows that the broadest range of drought severity includes parts of the east, north-east and south-eastern lake areas. This contrasts with spatial patterns as evidenced by the other two indicators. However, not much difference was found between the severe year 2015 and the extreme year 2018 in terms of snow drought patterns.

\subsubsection{Spatial Distribution of Drought Frequency}

Drought frequency (DF) is defined in terms of the number of drought events per 38 years. DF under -1 threshold maps indicate extreme conditions in the near lake region based on three drought indices. The drought frequency maps (Figure 13) show the difference between the drought frequency in the Urmia basin in terms of the three different indicators, SPI, SPEI, and SMRI. When considering SMRI data, the most extreme and prolonged events occurred in the Zarine river sub-catchment. Using SPI, all parts of the lake shore were affected by prolonged drought events, occurring in 30 out of 38 years, 
and drought patterns using the SPEI index show the prevalence of drought conditions ranging from the southern part of the lake to the southern parts of the basin for most years. It needs to be noted that in Figure 13, the SPI index only shows the occurrence of drought in the lake shore stations, while the SPEI index shows a relatively more expansive range of drought-affected areas. However, the SMRI index clearly identifies the drought area due to runoff deficiency in the south of the basin.

SPI

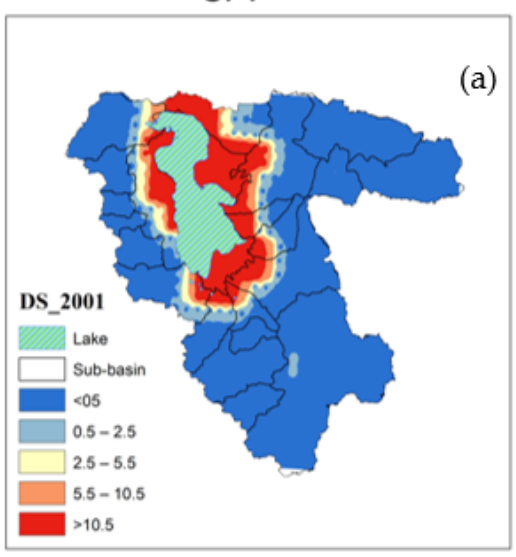

SPI

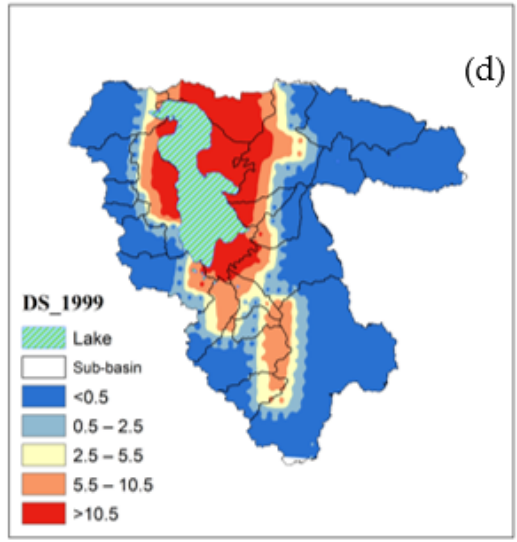

SPEI

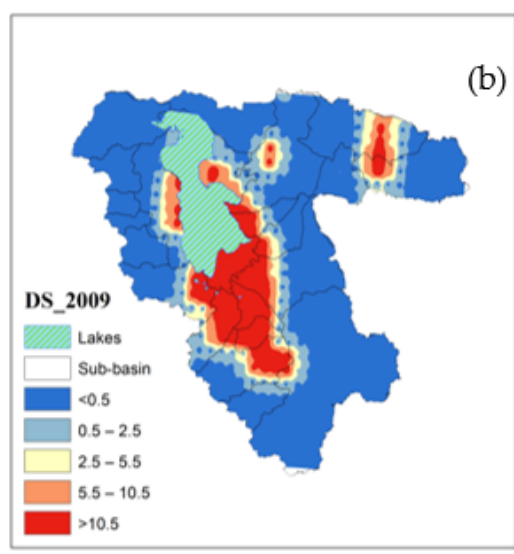

SPEI

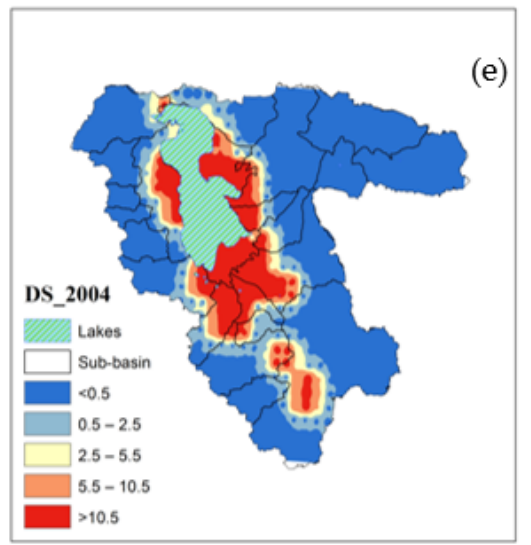

SMRI



SMRI

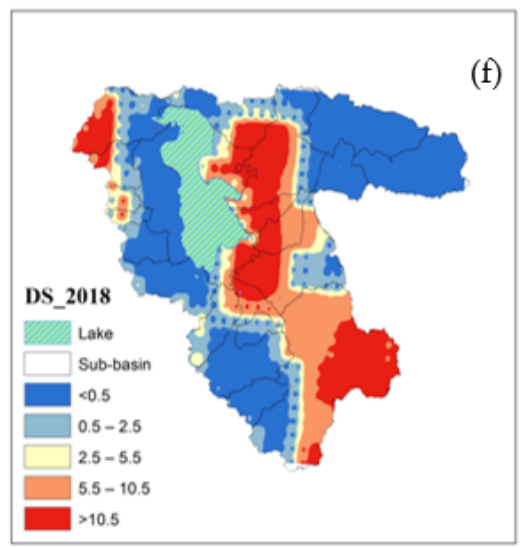

Figure 12. Drought Severity (DS) maps over ULB basin. (a) SPI dry year, (b) SPEI dry year, (c) SMRI dry year, (d) SPI drier year, (e) SPEI drier year and (f) SMRI drier year. Based on Table 2 threshold $<-1$ considered as drought hot spots [91].


Figure 13. Drought Frequency (DF) maps over ULB basin during 1981-2018. (a) SPI_DF, (b) SPEI_DF, (c) SMRI_DF. Based on Table 2 threshold $<-1$ considered as drought hot spots [91]. 


\section{Discussion}

The above comparison of drought events across the Urmia Lake Basin (ULB) has helped reveal specific drought behavior occurring over recent decades. The combined use of three common drought indices, i.e., SPI, SPEI, and SMRI, has provided clear insight into drought characteristics. Given the low density of meteorological stations, the inadequacies of existing statistics, the presence of geographical and topographical complexities (mountains, lowlands, and sea), an analysis of drought characteristics can only properly be carried out by making use of data with high spatial density. Therefore, the precipitation and temperature data of ERA5 were used to calculate drought indices. The suitability of the ERA5 dataset for purposes of drought monitoring was examined by making use of two series of data from observational and simulated ERA5. ROC and AUC (BSS) calculations were then used in order to check model performance. The results showed that the drought indices obtained by ERA5 are highly consistent with observational data and that they provide an excellent alternative to such data.

We also analyzed drought severity, duration, and frequency for various timescales, and additionally looked at spatial distribution, focusing on specific dry and wet events. There was a positive, significant, and robust correlation $(p$-value $<0.001)$ between the severity and duration of the drought, meaning that the more severe the drought occurrence, the longer its duration. The analysis revealed that both SMRI and SPEI are more suitable for capturing ULB drought characteristics than SPI. However, in recent decades, drought conditions as reflected by SPEI have been more severe than those indicated by SPI. This is mainly due to the fact that the former index is capable of capturing the impact of an increase in mean temperatures in the basin area. Furthermore, SMRI index data also exhibit a rising trend in drought conditions. The results above confirmed that the SMRI-type drought has become more abundant in recent years-especially since 2010 - than other types of droughts (SPI and SPEI). This may be due to rising basin temperatures and global warming having led to a decrease in snowfall in the basin in the last decades, resulting in a decrease in snowmelt surface water and an increase in the SMRI drought sequence. In general, it can be confirmed that SMRI and SPEI indices are capable of capturing more real drought conditions in the basin than the SPI index. We found that the most extended periods of snowmelt-related drought, as measured by the SMRI, mainly occurred in the more recent years of the study period, i.e., in 2010, 2015, and 2018. While the SPI also indicates a few moderate to extreme (index $\leq-1$ ) drought events, there is a clear and significant rising trend in extreme SPEI and SMRI drought. Our study has benefitted greatly from being able to make use of advances in SMRI data and from the availability of high-resolution ERA5 datasets.

Further tools are likely to become more widely available for investigating the possible relationships between climate data and water level or streamflow. For example, the use of robust wavelet analysis methods, such as the Least-Squares Cross-Wavelet Analysis (LSCWA) and the cross-wavelet transform, appears promising. Wavelet analysis can also show inter-annual and intra-annual variability within the climate and hydrological time series [92]. The scope for future research possibilities in the field thus remains undiminished.

\section{Conclusions}

The temporal evolution of drought indices was investigated to better understand the causes of drought in the ULB. This is the first time that the relevance of snow cover has been taken into account in analyzing drought in the ULB basin. In characterizing drought events, variables such as drought frequency, duration, and severity all need to be carefully examined. As the number of weather stations in the ULB is limited, and adequate data was lacking, ERA5 reanalysis data was drawn upon in order to capture drought behavior in the basin in a spatially consistent manner. ROC curves and BSS scores confirmed the ability of ERA5 to capture drought events in the catchment area. We found that the ERA5-based 
drought indices mainly capture dry events in the ULB well but are not as good at capturing wet events.

While drought events occurring before 1995 were mostly precipitation-driven (SPI), and reached a peak around 2000, ET (SPEI) and snowmelt-driven events (SMRI) were basically absent before 1995. Precipitation-driven droughts show no trend since 1980, while drought driven by evaporation and lack of snowmelt showed a marked increase since around 1995. In fact, the severe droughts found on the long timescale (12 months) in 2015 and 2018, were mainly driven by snowmelt. Other studies have also confirmed an increase in such drought events. Drought severity and duration in the ULB also appear to be highly interdependent (shown by means of correlation), i.e., there has been an increase in the severity of drought events, and their duration.

Although there has been no severe SPI drought in the last few decades, the water level in Lake Urmia has continued to decrease. This suggests that drought in the ULB is most likely due to non-sustainable water management, or to an increase in evaporation caused by global warming (and is not a direct result of rainfall variability). Most importantly, the results also show that snow droughts have not only been more frequent and severe in recent years but have also affected an increasing area over time. According to the snow drought index results, most extreme events were observed in the Zarinehrood and Siminehrood sub-basins, both of which play an important role in the revitalization of the lake.

Author Contributions: All authors contributed to the study's conception and design. M.H. undertook data preparation and processing and provided all maps. She also wrote the first draft of the manuscript. W.S. supervised the project and was the original source for the main idea. He also had a significant role in editing, reviewing, and finalizing the results. I.B. finalized the draft text and performed editing and reviewing. He was also active in gathering and reviewing data and was responsible for the statistical calculations. All authors have read and agreed to the published version of the manuscript.

Funding: This paper is academic research, and the authors declare that they have received funds from the University of Graz. Open Access Funding by the University of Graz.

Data Availability Statement: The datasets analyzed during the current study are available in the ERA5-ECMWF dataset repository (ERA5 I ECMWF), and stationary data are available in IRIMO.

Acknowledgments: The authors acknowledge the financial support provided by the University of Graz. We would like to thank all the Data providers. Data were provided by Iran Meteorological Organization, the European Centre for Medium-Range Weather Forecasts (ECMWF) and Integrated Climate Data Center-ICDC.

Conflicts of Interest: The authors declare that they have no conflict of interest.

\section{References}

1. Collins, M.; Knutti, R.; Arblaster, J.; Dufresne, J.-L.; Fichefet, T.; Friedlingstein, P.; Gao, X.; Gutowski, W.J.; Johns, T.; Krinner, G.; et al. Chapter 12-Long-Term Climate Change: Projections, Commitments and Irreversibility. In Climate Change 2013: The Physical Science Basis. IPCC Working Group I Contribution to AR5; IPCC Cambridge, Ed.; Cambridge University Press: Cambridge, UK, 2013.

2. Lu, J.; Carbone, G.J.; Grego, J.M. Uncertainty and hotspots in 21st century projections of agricultural drought from CMIP5 models. Sci. Rep. 2019, 9, 1-12. [CrossRef] [PubMed]

3. Barlow, M.; Zaitchik, B.; Paz, S.; Black, E.; Evans, J.; Hoell, A. A Review of Drought in the Middle East and Southwest Asia. J. Clim. 2016, 29, 8547-8574, Retrieved 11 February 2021. [CrossRef]

4. Agrawala, S.; Barlow, M.; Cullen, H.; Lyon, B. The drought and humanitarian crisis in central and southwest Asia: A climate perspective. IRI Rep. 2001, 24. [CrossRef]

5. Lautze, S.; Stites, E.; Nojumi, N.; Najimi, F. Qaht-e-Pool-A Cash Famine: Food Insecurity in Afghanistan 1999-2002; Feinstein International Center, Tufts University: Boston, MA, USA, 2002.

6. Daryabari, S.J. Drought zoning of Iran in the past 50 years. J. Geogr. 2011, 82, 33-48.

7. Azadi, S.; Soltani, S.; Faramarzi, M.; Poumanafi, S. Calibration of Palmer drought index over Iran. J. Iran's Water Res. 2018, 2, 19-28.

8. Alijani, B.; Babaei-Fini, O. Spatial analysis of short-term drought in Iran. J. Geogr. Reg. Plan. 2009, 1, $109-121$.

9. Babaei-Fini, O.; Alijani, B. Spatial analysis of long duration drought in Iran. J. Phys. Geogr. Res. Q. 2013, 45, 1-12. [CrossRef] 
10. Daneshmand, H.; Mahmoudi, P. A spectral analysis of Iran's droughts. Iran. J. Geophys. 2017, 10, $28-47$.

11. Nejad, M.T.; Hejazizadeh, Z.; Bosak, A.; Bazmi, N. The Effects of North Atlantic Oscillation on the atmospheric middle level Anomaly and precipitation of Iran. Case study: West of Iran. Res. Geogr. Sci. 2018, 18, 19-35. [CrossRef]

12. Azizi, G. Elnino and dry and wet period of Iran. J. Geogr. Res. 2000, 32, 71-84.

13. Khoshakhlagh, F.; Azixi, G.; Rahimi, M. Synoptic pattern of dry and wet winters over Southwest of Iran. J. Appl. Res. Geogr. Sci. 2012, 12, 57-77.

14. Babaeia-Fini, O.; Fattahi, E. Classification of synoptic patterns wet and dry condition over Iran. J. Appl. Res. Geogr. Sci. 2015, 29, 105-122.

15. Babaeian, I.; Rezazadeh, P. On the relationship between Indian monsoon withdrawal and Iran's fall precipitation onset. Theor. Appl. Climatol. 2018, 134, 95-105. [CrossRef]

16. Ghamghami, M.; Irannejad, P. An analysis of droughts in Iran during 1988-2017. SN Appl. Sci. 2019, 1, 1217. [CrossRef]

17. Farokhnia, A.; Morid, S. Assessment of the Effects of Temperature and Precipitation Variations on the Trend of River Flows in Urmia Lake Watershed. J. Water Wastewater 2014, 25, 86-97.

18. Fathian, F.; Morid, S.; Kahya, E. Identification of trends in hydrological and climatic variables in Urmia Lake basin, Iran. Theor. Appl. Clim. 2015, 119, 443-464. [CrossRef]

19. Zarghami, M. Effective watershed management; case study of Urmia Lake, Iran. Lake Reserve Manag. 2011, 27, 87-94. [CrossRef]

20. Delju, A.H.; Ceylan, A.; Piguet, E.; Rebetez, M. Observed climate variability and change in Urmia Lake Basin, Iran. Theor. Appl. Climatol. 2013, 111, 285-296. [CrossRef]

21. Azizzadeh, M.R.; Javan, K. Temporal and spatial distribution of extreme precipitation indices over the lake Urmia Basin, Iran. Environ. Resour. Res. 2018, 6, 25-40.

22. Tahroudi, M.N.; Ramezani, Y.; Ahmadi, F. Investigating the trend and time of precipitation and river flow rate changes in Lake Urmia basin, Iran. Arab. J. Geosci. 2019, 12, 219. [CrossRef]

23. AghaKouchak, A.; Norouzi, H.; Madani, K.; Mirchi, A.; Azarderakhsh, M.; Nazemi, A.; Nasrollahi, N.; Farahmand, A.; Mehran, A.; Hasanzadeh, E. Aral Sea syndrome desiccates Lake Urmia: Call for action. J. Great Lakes Res. 2015, 41, 307-311. [CrossRef]

24. Alizadeh-Choobari, O.; Ahmadi-Givi, F.; Mirzaei, N.; Owlad, E. Climate change and anthropogenic impacts on the rapid shrinkage of Lake Urmia. Int. J. Climatol. 2016, 36, 4276-4286. [CrossRef]

25. Eimanifar, A.; Mohebbi, F. Urmia Lake (Northwest Iran): A brief review. Saline Syst. 2007, 3, 5. [CrossRef]

26. Hassanzadeh, E.; Zarghami, M.; Hassanzadeh, Y. Determining them main factors in declining the Urmia Lake level by using system dynamics modeling. Water Resour. Manag. 2012, 26, 129-145. [CrossRef]

27. Jalili, S.; Kirchner, I.; Livingstone, D.M.; Morid, S. The influence of largescale atmospheric circulation weather types on variations in the water level of Lake Urmia, Iran. Int. J. Climatol. 2011, 32, 1990-1996. [CrossRef]

28. Javanshiri, Z.; Pakdaman, M.; Falamarzi, Y. Homogenization, and trend detection of temperature in Iran for the period 1960-2018. Meteorol. Atmos. Phys. 2021, 133, 1233-1250. [CrossRef]

29. Azizi, G.; Nazif, S.; Abbasi, F. Assessment of performance of Urmia basin dams using system dynamic approach. J. Arid Reg. Geogr. Stud. 2016, 7, 48-63.

30. Shadkam, S.; Ludwig, F.; van Oel, P.; Kirmit, Ç.; Kabat, P. Impacts of climate change and water resources development on the declining inflow into Iran's Urmia Lake. J. Great Lakes Res. 2016, 42, 942-952. [CrossRef]

31. Ghaheri, M.; Baghal-Vayjooee, M.H.; Naziri, J. Lake Urmia, Iran: A summary review. Int. J. Salt Lake Res. 1999, 8, 19-22. [CrossRef]

32. Kakahaji, H.; Banadaki, H.D.; Kakahaji, A. Prediction of Urmia Lake Water-Level Fluctuations by Using Analytical, Linear Statistic and Intelligent Methods. Water Resour. Manag. 2013, 27, 4469-4492. [CrossRef]

33. Karbassi, A.; Bidhendi, G.N.; Pejman, A.; Bidhendi, M.E. Environmental impacts of desalination on the ecology of Lake Urmia. J. Great Lakes Res. 2010, 36, 419-424. [CrossRef]

34. Lweendo, M.K.; Lu, B.; Wang, M.; Zhang, H.; Xu, W. Characterization of droughts in humid subtropical region, upper kafue river basin (Southern Africa). Water 2017, 9, 242. [CrossRef]

35. Davarpanah, S.; Erfanian, M.; Javan, K. Assessment of Climate Change Impacts on Drought and Wet Spells in Lake Urmia Basin. Pure Appl. Geophys. 2021, 178, 545-563. [CrossRef]

36. Ginoux, P.A.; Prospero, J.M.; Gill, T.E.; Hsu, C.; Zhao, M. Global-scale attribution of anthropogenic and natural dust sources and their emission rates based on MODIS Deep Blue aerosol products. Rev. Geophys. 2012, 50, RG3005. [CrossRef]

37. Palmer, W.C. Meteorological Drought, Office of Climatology. US Weather Bureau, Research Paper. 1965. No. 45. Available online: https://www.ncdc.noaa.gov/temp-and-precip/drought/docs/palmer.pdf (accessed on 9 October 2021).

38. Gibbs, W.J.; Maher, J.V. 1916-1993 \& Australia. Bureau of Meteorology. In Rainfall Deciles as Drought Indicators; Bureau of Meteorology: Melbourne, Australia, 1967.

39. McKee, T.B.; Doesken, N.J.; Kleist, J. The relationship of drought frequency and duration to time scale. In Proceedings of the Eighth Conference on Applied Climatology, Anaheim, CA, USA, 17-22 January 1993; American Meteorological Society: Boston, MA, USA; pp. 179-184.

40. Palmer, W.C. Keeping track of crop moisture conditions, nationwide: The new Crop Moisture Index. Weather 1968, $21,156-161$. [CrossRef] 
41. Shafer, B.A.; Dezman, L.E. Development of a surface water supply index (SWSI) to assess the severity of drought conditions in snowpack runoff areas. In Proceedings of the Western Snow Conference; Colorado State University: Fort Collins, CO, USA, 1982; pp. 164-175.

42. Kogan, F.N. Global droughts watch from space. Bull. Am. Meteorol. Soc. 1997, 78, 621-636. [CrossRef]

43. Kogan, F.N. World droughts in the new millennium from AVHRR-based vegetation health indices. Eos Trans. Am. Geophys. Union 2002, 83, 562-563. [CrossRef]

44. Keyantash, J.; Dracup, J.A. An aggregate drought index: Assessing drought severity based on fluctuations in the hydrologic cycle and surface water storage. Water Resour. Res. 2004, 40, W09304. [CrossRef]

45. Bhuiyan, C.; Singh, R.P.; Kogan, F.N. Monitoring drought dynamics in the Aravalli region (India) using different indices based on ground and remote sensing data. Int. J. Appl. Earth Obs. Geoinf. 2006, 8, 289-302. [CrossRef]

46. Abbas, S.; Nichol, J.E.; Qamer, F.M.; Xu, J. Characterization of drought development through remote sensing: A case study in Central Yunnan, China. Remote Sens. 2014, 6, 4998-5018. [CrossRef]

47. Cunha, A.P.M.; Alvalß, R.C.; Nobre, C.A.; Carvalho, M.A. Monitoring vegetative drought dynamics in the Brazilian semiarid region. Agric. For. Meteorol. 2015, 214, 494-505. [CrossRef]

48. Hollinger, S.E.; Isard, S.A.; Welford, M.R. A new soil moisture drought index for predicting crop yields. In Preprints, Eighth Conference on Applied Climatology; American Meteorological Society: Anaheim, CA, USA, 1993; pp. 187-190.

49. Meyer., S.J.; Hubbard, K.G.; Wilhite, D.A. A crop-specific drought index for corn: I. Model development and validation. Agron. J. 1993, 86, 388-395. [CrossRef]

50. Weghorst, K.M. The Reclamation Drought Index: Guidelines and Practical Applications; Bureau of Reclamation: Denver, CO, USA, 1996; p. 6.

51. Vicente-Serrano, S.M.; Beguería, S.; López-Moreno, J.I. A Multi-scalar drought index sensitive to global warming: The Standardized Precipitation Evapotranspiration Index-SPEI. J. Clim. 2010, 23, 1696-1718. [CrossRef]

52. Staudinger, M.; Stahl, K.; Seibert, J. A drought index accounting for snow. Water Resour. Res. 2014, 50, 7861-7872. [CrossRef]

53. Muhammad, A.; Kumar Jha, S.; Rasmussen, P.F. Drought characterization for a snowdominated region of Afghanistan. J. Hydrol. Eng. 2017, 22, 5017014. [CrossRef]

54. Hatchett, B.J.; McEvoy, D.J. Exploring the origins of snow drought in the northern Sierra Nevada, California. Earth Interact. 2018, 22, 1-13. [CrossRef]

55. Dierauer, J.R.; Allen, D.M.; Whitfield, P.H. Snow drought risk and susceptibility in the western United States and southwestern Canada. Water Resour. Res. 2019, 55, 3076-3091. [CrossRef]

56. Margulis, S.A. Characterizing the extreme 2015 snowpack deficit in the Sierra Nevada (USA) and the implications for drought recovery. Geophys. Res. Lett. 2016, 43, 6341-6349. [CrossRef]

57. Zhang, H.-M. Updated temperature data give a sharper view of climate trends. Eos Trans. Am. Geophys. Union 2019, 100, 1961-2018. [CrossRef]

58. Huning, S.L.; AghaKouchak, A. Global snow drought hot spots and characteristics. Proc. Natl. Acad. Sci. USA 2020, 117, 19753-19759. [CrossRef] [PubMed]

59. Ghaderpour, E.; Vujadinovic, T.; Hassan, Q.A. Application of the Least-Squares Wavelet software in hydrology: Athabasca River Basin. J. Hydrol. Reg. Stud. 2021, 36, 100847. [CrossRef]

60. Zhang, J.; Zheng, H.; Zhang, X.; VanLooy, J. Changes in Regional Snowfall in Central North America (1961-2017): Mountain Versus Plains. Geosciences 2020, 10, 157. [CrossRef]

61. Littell, J.S.; McAfee, S.A.; Hayward, G.D. Alaska.Snowpack Response to Climate Change: Statewide Snowfall Equivalent and Snowpack Water Scenarios. Water 2018, 10, 668. [CrossRef]

62. Van Loon, A.F.; Van Lanen, H.A.J. A process-based typology of hydrological drought. Hydrol. Earth Syst. Sci. 2012, 16, 1915-1946. [CrossRef]

63. Tijdeman, E. Natural and Human Influences on the Link Between Meteorological and Hydrological Drought Indices for a Large Set of Catchments in the Contiguous United States. Water Resour. Res. 2018, 54, 6005-6023. [CrossRef]

64. Hydrological Data. 2015. Available online: https://www.ulrp.ir/en/hydrological-data/ (accessed on 1 January 2020).

65. Hersbach, H.; Bell, B.; Berrisford, P.; Horányi, A.; Sabater, J.M.; Nicolas, J.; Radu, R.; Schepers, D.; Simmons, A.; Soci, C.; et al. Global reanalysis: Goodbye ERA-Interim, hello ERA5. ECMWF Newsl. 2019, 159, 17-24. [CrossRef]

66. Fallah, A.; Rakhshandehroo, G.R.; Sungmin, P.; Orth, R. Evaluation of precipitation datasets against local observations in southwestern Iran. Int. J. Climatol. 2019, 40, 4102-4116. [CrossRef]

67. Yazdandoost, F.; Moradian, S.; Zakipour, M.; Izadi, A.; Bavandpour, M. Improving the precipitation forecasts of the North American multi model ensemble (NMME) over Sistan basin. J. Hydrol. 2020, 590, 125263. [CrossRef]

68. Azizi mobaser, J.; Rasoulzadeh, A.; Rahmati, A.; Shayeghi, A.; Bakhtar, A. Evaluating the Performance of Era-5 Re-Analysis Data in Estimating Daily and Monthly Precipitation, Case Study; Ardabil Province. Iran. J. Soil Water Res. 2021, 51, $2937-2951$. [CrossRef]

69. Izadi, N.; Karakani, E.G.; Saadatabadi, A.R.; Shamsipour, A.; Fattahi, E.; Habibi, M. Evaluation of ERA5 Precipitation Accuracy Based on Various Time Scales over Iran during 2000-2018. Water 2021, 13, 2538. [CrossRef] 
70. Beguería, S.; Vicente-Serrano, S.; Reig, F.; Latorre, B. Standardized Precipitation Evapotranspiration Index (SPEI) revisited: Parameter fitting, evapotranspiration models, tools, datasets and drought monitoring. Int. J. Climatol. 2014, 34, $3001-3023$. [CrossRef]

71. Smakhtin, V.U.; Hughes, D.A. Review, Automated Estimation and Analyses of Drought Indices in South Asia; IWMI Working Paper 083: Drought Series Paper 1; International Water Management Institute (IWMI): Sri Lanka, CO, USA, 2004; 24p.

72. Guttman, N.B. Comparing the Palmer Drought Index and the Standardized Precipitation Index. JAWRA J. Am. Water Resour. Assoc. 1998, 34, 113-121. [CrossRef]

73. Středová, H.; Středa, T.; Chuchma, F. Climatic Factors of Soil Estimated System. In Bioclimate: Source and Limit of Social Development; SPU v Nitre: Nitra, Slovakia, 2011; pp. 137-138. ISBN 978-80-552-0640.

74. Hernandez, E.A.; Uddameri, V. Standardized Precipitation Evaporation Index (SPEI)-based drought assessment in semi-arid south Texas. Environ. Earth Sci. 2014, 71, 2491-2501. [CrossRef]

75. Thornthwaite, C.W. An approach toward a rational classification of climate. Geogr. Rev. 1948, 38, 55-94. [CrossRef]

76. Abramowitz, M.; Stegun, I.A. Handbook of Mathematical, Functions; National Bureau of Standards: Washington, DC, USA, 1965.

77. Abramowitz, M.; Stegun, I.A. Handbook of Mathematical Functions: With Formulas, Graphs and Mathematical Tables; Cambridge University Press: Cambridge, UK; Courier Corporation: Chelmsford, MA, USA, 1964.

78. Hosking, J.R.M.; Wallis, J.R. Regional Frequency Analysis: An Approach Based on L-Moments; Cambridge University Press: Cambridge, UK, 2005. [CrossRef]

79. Byakatonda, J.; Parida, B.P.; Kenabatho, P.K.; Moalafhi, D.B. Modeling dryness severity using artificial neural network at the Okavango Delta, Botswana. Glob. Nest J. 2016, 18, 463-481. [CrossRef]

80. Freudiger, D.; Kohn, I.; Stahl, K.; Weiler, M. Large-scale analysis of changing frequencies of rain-on-snow events with floodgeneration potential. Hydrol. Earth Syst. Sci. 2014, 18, 2695-2709. [CrossRef]

81. Hogan, J.E.; Phillips, F.M.; Scanlon, B.R. Groundwater Recharge in a Desert Environment: The Southwestern United States; American Geophysical Union: Washington, DC, USA, 2004; Volume 9. [CrossRef]

82. Mishra, A.K.; Singh, V.P.; Desai, V.R. Drought characterization: A probabilistic approach. Stoch. Environ. Res. Risk Assess. 2009, 23, 41. [CrossRef]

83. Spinoni, J.; Naumann, G.; Carrto, H.; Barbosa, P.; Vogt, J. World drought frequency, duration, and severity for 1951-2010. Int. J. Climatol. 2014, 34, 2792-2804. [CrossRef]

84. Spinoni, J.; Naumann, G.; Vogt, J.; Barbosa, P. European drought climatologies and trends based on a multi-indicator approach. Glob. Planet. Change 2015, 127, 50-57. [CrossRef]

85. Lee, S.H.; Yoo, S.H.; Choi, J.Y.; Bae, S. Assessment of the impact of climate change on drought characteristics in the Hwanghae plain, North Korea using time series SPI and SPEI: 1981-2100. Water 2017, 9, 579. [CrossRef]

86. Benjamin, B.M.; Michael, D.; Morphew, S. Developing Hydro-Meteorological Thresholds for Shallow Landslide Initiation and Early Warning. J. Water 2018, 10, 1274. [CrossRef]

87. Tisseuil, C.; Roshan, G.R.; Nasrabadi, T.; Asadpour, G. Statistical Modeling of Future Lake Level under Climatic Conditions, Case study of Urmia Lake (Iran). Int. J. Environ. Res. 2013, 7, 69-80. [CrossRef]

88. Schulz, S.; Darehshouri, S.; Hassanzadeh, E.; Tajrishy, M.; Schüth, C. Climate change or irrigated agriculture-What drives the water level decline of Lake Urmia. Sci. Rep. 2020, 10, 1-10. [CrossRef] [PubMed]

89. Schmidt, M.; Gonda, R.; Transiskus, S. Environmental degradation at Lake Urmia (Iran): Exploring the causes and their impacts on rural livelihoods. GeoJournal 2021, 86, 2149-2163. [CrossRef]

90. Iranian Students News Agency (ISNA). 96 Large Dams Have Less than 40\% Water Storage. Available online: https:/ / www.isna. $\mathrm{ir} /$ news /97091105033/ (accessed on 30 September 2021).

91. Brito, S.S.B.; Cunha, A.P.M.A.; Cunningham, C.C.; Alvalá, R.C.; Marengo, J.A.; Carvalho, M.A. Frequency, duration, and severity of drought in the Semiarid Northeast Brazil region. Int. J. Climatol. 2017, 38, 517-529. [CrossRef]

92. Canchala, T.; Cerón, W.L.; Francés, F.; Carvajal-Escobar, Y.; Andreoli, R.V.; Kayano, M.T.; Alfonso-Morales, W.; Caicedo-Bravo, E.; de Souza, R.A.F. Streamflow Variability in Colombian Pacific Basins and Their Teleconnections with Climate Indices. Water 2020, 12, 526. [CrossRef] 